This is final peer-reviewed manuscript accepted for publication in Langmuir 33, 12155-12170, 2017, DOI: 10.1021/acs.langmuir.7b02048

\title{
Mechanisms and control of self-emulsification upon freezing and melting of dispersed alkane drops
}

\author{
Zhulieta Valkova, ${ }^{1}$ Diana Cholakova, ${ }^{1}$ Slavka Tcholakova, ${ }^{1}$ \\ Nikolai Denkov, ${ }^{1}$ and Stoyan K. Smoukov*1,2,3 \\ ${ }^{1}$ Department of Chemical \& Pharmaceutical Engineering \\ Faculty of Chemistry \& Pharmacy, Sofia University, Bulgaria
}

${ }^{2}$ Active and Intelligent Materials Laboratory, School of Engineering and Materials Science, Queen Mary University of London, Mile

End Road, London E1 4NS, U.K.

${ }^{3}$ Active and Intelligent Materials Lab, Department of Materials Science \& Metallurgy, University of Cambridge, $U K$

*Corresponding author:

Stoyan Smoukov

Phone: +44 2078825305

Fax: (01223) 762088

E-mail: s.smoukov@qmul.ac.uk

Keywords: self-emulsification, drop self-shaping, melt-crystal fragmentation, drop breakage, phase change materials, capillary instability. 


\begin{abstract}
Emulsification requires drop breakage and creation of large interfacial area between immiscible liquid phases. Usually, high shear or high pressure emulsification devices which generate heat and increase emulsion temperature are used to obtain emulsions with micrometer and submicrometer droplets. Recently we reported a new efficient procedure of self-emulsification (Tcholakova et al. Nature Comm. 2017, 8:15012) which consists of one to several cycles of freezing and melting of pre-dispersed alkane drops in coarse oil-in-water emulsion. Within these freeze-thaw cycles of the dispersed drops, the latter burst spontaneously into hundreds and thousands of smaller droplets, without using any mechanical agitation. Here we clarify the main factors and the mechanisms which drive this self-emulsification process by exploring systematically the effects of the oil and surfactant types, the cooling rate, and the initial drop size. We show that the typical size of the droplets, generated by this method, is controlled by the size of the structural domains, formed in the cooling/freezing stage of the procedure. Depending on the leading mechanism, these could be the diameter of the fibers formed upon drop selfshaping or the size of the crystal domains formed in the moment of drop freezing. Generally, surfactant tails which are 0 to 2 carbon atoms longer than the oil molecules are most appropriate to observe efficient self-emulsification. The specific requirements for realization of the different mechanisms are clarified and discussed. The relative efficiencies of the three different mechanisms, as a function of droplet size and cooling procedure, are compared in controlled experiments to provide guidance for understanding and further optimization and scaleup of this self-emulsification process.
\end{abstract}




\section{Introduction}

Many common industrial and consumer products, including paints, shampoos, lotions, cosmetic creams, salad dressings, mayonnaise and some pharmaceutical formulations are emulsions (liquid-in-liquid dispersions). Therefore, the emulsification processes are widely used in various chemical, pharmaceutical, agro, food and cosmetic technologies. ${ }^{1-3}$

The emulsification is typically performed with high-shear or high-pressure devices which generate sufficiently high viscous or inertial hydrodynamic stresses, able to deform and disrupt the emulsion drops into the desired micrometer and submicrometer sizes. ${ }^{1-7}$ The energy dissipated in the classical emulsification devices is several orders of magnitude higher than the interfacial energy of the small droplets generated. ${ }^{1-3}$ Thus, emulsification is an energy intensive process with most of energy wasted into heat. Furthermore, the dissipated energy may increase the temperature of the processed emulsion by dozens of degrees which might have a deteriorating effect on technological emulsions, containing temperature-sensitive components, such as the bio-active molecules in pharma, cosmetic and agro applications. ${ }^{1-3}$

Several techniques have been explored to address the need to handle temperature-sensitive formulations. Membrane emulsification enables low temperature emulsification at the expense of lower productivity and limited drop size range, which does not include the sub-micrometer domain. $^{8-9}$ As a result of these limitations, the membrane emulsification, though being highly energy efficient, has found a limited application outside the research labs.

Several other techniques, based on a spontaneous drop fragmentation (self-emulsification) were proposed for generation of micrometer and sub-micrometer droplets. ${ }^{10-18}$ Some of these techniques are based on the reduction of the oil solubility in the continuous medium which could be either a mixture of solvents or surfactant-based microemulsion. ${ }^{16-18}$ By changing the solvent composition and/or temperature, one could reduce the oil solubility and thus generate tiny droplets of nanometer size. These methods require rather high solubility or solubilization of the oil in the continuous medium in order to generate emulsions of reasonably high drop volume fraction. Therefore, either polar oils with relatively small molecules (in the case of solvent precipitation) or rather high surfactant concentration (in the case of microemulsions) are needed to apply this approach.

Another class of self-emulsification methods utilizes changes in the solvent composition, surfactant composition or temperature to inverse an initially water-in-oil into oil-in-water emulsion, or vice versa. ${ }^{12-13}$ In this phase inversion process small droplets may be formed, although important elements in the mechanism of drop fragmentation are still unclear. Usually, the phase inversion techniques are explained with the change of the spontaneous curvature of the 
interfacial surfactant layer, so that the preferred enclosed phase changes from oil to water, or vice versa. These techniques also require surfactants of relatively high concentrations and this requirement creates problems for many, potentially useful applications. Therefore, other low temperature and low energy emulsification processes with high productivity are needed to advance our current technologies.

Recently, we demonstrated a novel low-energy and low-temperature self-emulsification process, in which the oil droplets in an oil-in-water emulsion break up spontaneously into much smaller droplets in the course of a temperature cycling around the freezing temperature of the oil drops. The typical temperature cycle includes slow cooling, freezing of the drops, and their remelting. Repeating these cycles may lead, under appropriate conditions, to the formation of droplets with sub-micrometer diameter. Optical microscopy observations showed that this selfemulsification technique involves three non-trivial mechanisms of drop bursting. ${ }^{19}$

In the current study we present each of the newly discovered mechanisms in more details and clarify the effect of the main factors, viz. alkane and surfactant types, cooling rate and initial drop size, on each of these mechanisms and on the overall self-emulsification process.

Hereafter we explain briefly the shape transformations observed during the cooling stage of the temperature cycling (before the complete drop freezing) because these transformations are intimately related to the self-emulsification mechanisms, discussed in the current paper. In our recent studies ${ }^{20-22}$, we showed that micrometer emulsion drops from alkanes, alkenes, alcohols, triglycerides, asymmetric alkanes, mixtures of these compounds, and even mixtures of some commercial oils (e.g. cocoa butter, lard and coconut oil) with a small amount of linear alkane, ca. 15 vol. \% or higher, can self-shape upon cooling when long-chain surfactants are used as emulsion stabilizer, see Figure 1A. The long-chain surfactant forms adsorption layers on the drop surface which freeze upon cooling before the freezing of the oil in the drop interior. ${ }^{20,21,23}$ In this way, the frozen adsorption layer creates a surface template for formation of the so-called "plastic rotator phase" beneath the drop surface, Figure 1B. The molecules in such plastic phase have a long-range translational order and some rotational freedom along their long axes. The plastic rotator phases are known for years to appear as intermediate phases between the isotropic liquid and the fully frozen solid state of the cooled alkanes. ${ }^{24-30}$

The plastic phases possess certain elasto-plastic mechanical strength. Therefore, the appearance of a plastic phase at the drop surface leads to deformation of the emulsion drops. The optical observations show that the drops deform first into polyhedra which rapidly flatten to form hexagonal, tetragonal or trigonal platelets. This sequence of shape transformations was explained with the formation of an expanding frame of cylindrical rods of plastic phase at the drop 
periphery. The partial mobility of the molecules assembled in the rotator phase allows for molecular exchange and dynamic equilibrium with the neighboring liquid alkane. As a result, the plastic frame expands and re-shape with time, "sucking" molecules from the liquid interior of the platelet, and thus "pushes" the oil-water interface, forming various geometric shapes as shown in Figure 1A. A theoretical model was developed around these ideas which explained the observed platelet shape sequence and is in agreement with the experiment. ${ }^{31}$ In their further shape evolution, the cooled drops may form long thin fibres (threads) protruding from the corners of the trigonal and tetragonal platelets. Eventually, the platelets may undergo a kind of capillary instability, forming ellipsoidal drops which extrude thin and very long fibers. Depending on the specific oil-surfactant pair and the cooling protocol, the droplets may freeze completely into solid particles in any of these shapes. In addition, the drops may break into smaller droplets during cooling and upon melting.

The paper is organized in the following way. Section 2 describes the materials and methods used. Sections 3.1 to 3.3 describe each of the mechanisms of self-emulsification and how these mechanisms respond to changes in alkane, surfactant, drop size and cooling rate. In section 3.4 we compare the effectiveness of these mechanisms and discuss how one could control the different factors to obtain an emulsion with a desired drop size distribution.

(A)

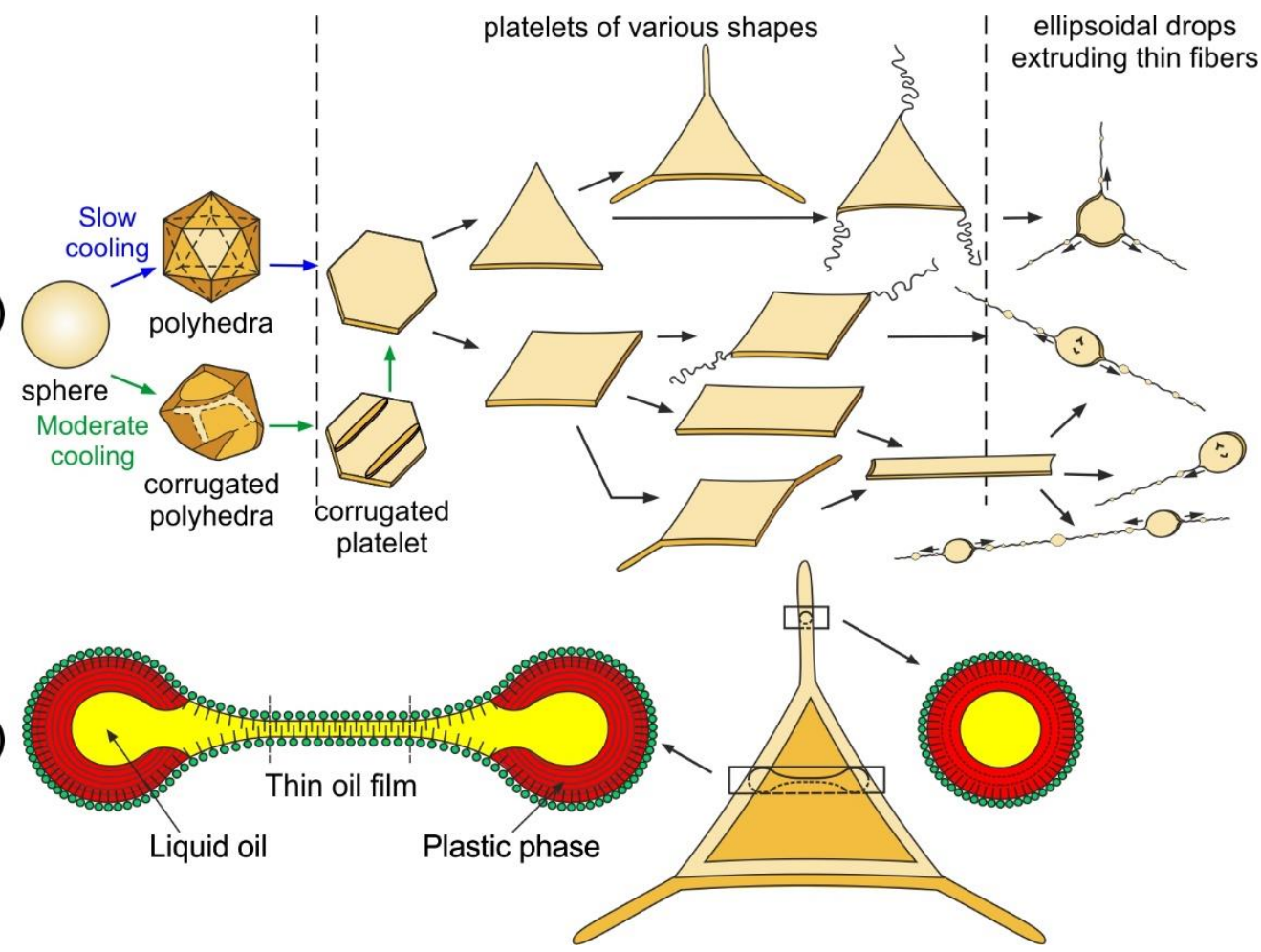

Figure 1. (A) Drop shape evolutionary scheme, showing the main stages through which the oily drops pass upon cooling. (B) Schematic presentation of the mechanism causing drop shape transformations; for more details see refs. 20-22, 31. 


\section{Materials and methods.}

\subsection{Materials.}

Linear alkanes with different chain lengths were used as dispersed oily phase in the studied emulsions. Tetradecane (referred to as $\left.\mathrm{C}_{14}\right)$, pentadecane $\left(\mathrm{C}_{15}\right)$, hexadecane $\left(\mathrm{C}_{16}\right)$, heptadecane $\left(\mathrm{C}_{17}\right)$, octadecane $\left(\mathrm{C}_{18}\right)$, nonadecane $\left(\mathrm{C}_{19}\right)$ and eicosane $\left(\mathrm{C}_{20}\right)$ were all products of Sigma-Aldrich with purity $>99 \%$. Their melting temperatures, $T_{\mathrm{m}}$, vary between $5.5{ }^{\circ} \mathrm{C}$ for $\mathrm{C}_{14}$ and $37{ }^{\circ} \mathrm{C}$ for $\mathrm{C}_{20}$. Detailed information for the physical properties of these alkanes is presented in Supporting Information Table S1. All alkanes were used as received, without further purification.

To stabilize the emulsions, we used a variety of nonionic and ionic surfactants. The nonionic surfactants were from two main groups - polyoxyethylene alkyl ethers $\left(\mathrm{C}_{n} \mathrm{EO}_{m}\right)$ and polyoxyethylene sorbitan monoalkylates $\left(\mathrm{C}_{n} \mathrm{SorbEO}_{20}\right)$ which differ in the length of their alkyl chain, $n$, varied between 12 and 22, and in the number of oxyethylene units, $m$, varied between 2 and 50. The $\mathrm{C}_{16} \mathrm{EO}_{2}$ surfactant is the only oil-soluble surfactant used, while the others are watersoluble surfactants. We used also three ionic surfactants - the cationic surfactants cetyltrimethylammonium bromide $\left(\mathrm{C}_{16} \mathrm{TAB}\right)$ and octadecyltrimethylammonium bromide $\left(\mathrm{C}_{18} \mathrm{TAB}\right)$, and the anionic sodium octadecyl sulfate $\left(\mathrm{C}_{18} \mathrm{SO}_{4} \mathrm{Na}\right)$. Detailed information for the purity, HLB values of the nonionic surfactants and surfactant producers is presented in Table S2. All surfactants were used as received.

For emulsion preparation, the emulsifier concentration in the aqueous solutions (1.5 wt \% for all nonionic surfactants, $0.37 \mathrm{wt} \%$ for the anionic surfactant, and $0.5 \mathrm{wt} \%$ for the cationic surfactants) was chosen to be sufficiently high as to suppress completely the drop-drop coalescence during the emulsion preparation and to avoid significant surfactant depletion during the experiments (due to adsorption on the increasing surface of the deforming drops).

All aqueous solutions were prepared with deionized water which was purified by Elix 3 module (Millipore, USA).

\subsection{Preparation of the initial emulsions.}

The initial alkane-in-water emulsions were prepared by a laboratory Microkit membrane emulsification module from Shirasu Porous Glass Technology (SPG, Miyazaki, Japan). The oil phase was passed through tubular glass membranes with outer diameter of $10 \mathrm{~mm}$ and working area of approximately $3 \mathrm{~cm}^{2}$. This method allows production of drops with relatively narrow drop size distribution. ${ }^{8,9,32-35}$ Membranes with mean pore diameter of $2 \mu \mathrm{m}, 3 \mu \mathrm{m}, 5 \mu \mathrm{m}$ and 
$10 \mu \mathrm{m}$ were used for preparing initial emulsions with drop diameters around $6 \mu \mathrm{m}, 11 \mu \mathrm{m}$, $17 \mu \mathrm{m}$ and $34 \mu \mathrm{m}$.

When preparing emulsions with substances which are solid at room temperature, we melt them by heating before emulsification and maintained sufficiently high temperature in the laboratory to avoid the liquid-solid phase transition before the actual emulsification experiments.

\subsection{Microscope observations of the freeze-thaw cycles.}

All observations were performed with optical microscope Axioplan or AxioImager.M2m (Zeiss, Germany). For the freeze-thaw cycles we used transmitted, cross-polarized white light with included $\lambda$ (compensator) plate, situated after the sample and before the analyser, at $45^{\circ}$ with respect to both the analyser and the polarizer. Under these conditions the liquid background and the fluid objects have typical magenta color, whereas the birefringent areas appear brighter and may have intense colors. ${ }^{36-37}$ When taking images for determination of the drop size distribution we used transmitted light. Long-focus objectives $20 \times, 50 \times$ and $100 \times$ were used.

A specimen of the studied emulsion was placed in a capillary with rectangular cross section: $50 \mathrm{~mm}$ length, $1 \mathrm{~mm}$ width, and $0.1 \mathrm{~mm}$ height. The capillary was enclosed within a custommade metal cooling chamber, with optical windows for microscope observation. The chamber temperature was controlled by cryo-thermostat (JULABO CF30, Cryo-Compact Circulator) and measured close to the emulsion location, using a calibrated thermo-couple probe with an accuracy of $\pm 0.2^{\circ} \mathrm{C}$ (Supplementary Figure S1). The thermo-probe was inserted in one of the orifices of the aluminum thermostatic chamber and mounted in the position, where a capillary with the emulsion sample would be normally placed for microscope observations. In the neighboring orifice the actual capillary with the emulsion sample was placed. The correct measurement of the temperature was ensured by calibrating the thermo-couple with a precise mercury thermometer in the respective range of temperatures measured. Furthermore, we always observe melting of the frozen particles at temperatures very close to $T_{\mathrm{m}} \pm 0.2^{\circ} \mathrm{C}$, where $T_{\mathrm{m}}$ is the melting temperature of the bulk oil, reported in the literature.

The freeze-thaw $(\mathrm{F} / \mathrm{T})$ experiments of the dispersed drops were performed as follows:

(1) The cooling process started at a temperature at least 5 degree higher than the bulk melting temperature of the studied alkane, see Table S1. The samples were cooled at a fixed cooling rate, varied in different experiments (usually, between 0.15 and $1.5 \mathrm{~K} / \mathrm{min}$ ). The temperature in the system was lowered until a complete freezing of the dispersed oil drops was observed. Note that only the dispersed phase underwent phase transitions during our experiments and solidified; the continuous medium (aqueous surfactant solution) remained always liquid. 
(2) The drop melting process was performed at a fixed heating rate, varied between 0.2 and $1.6 \mathrm{~K} / \mathrm{min}$. The temperature in the system was increased until reaching the initial temperature at which all dispersed entities were in a liquid state.

Procedures (1) and (2) may be repeated with the same sample to accomplish several consecutive F/T cycles.

\subsection{Determination of drop size distribution in the emulsions.}

The drop size distribution in emulsions was determined from microscope images, taken after each F/T cycle with $50 \times$ and $100 \times$ objectives. The accuracy in the measurements of the drop diameter by this method is $\pm 0.3 \mu \mathrm{m} .{ }^{38}$ Drop diameters were measured one by one, using custommade image analysis software. The diameters of more than 1000 droplets in each sample were measured.

The mean volume-surface diameter was determined from the relation $d_{32}=\sum_{i} N_{i} d_{i}^{3} / \sum_{i} N_{i} d_{i}^{2}$, where $N_{\mathrm{i}}$ is the number of drops with diameter $d_{\mathrm{i}}$. The maximal diameter by number, $d_{\mathrm{N} 95}$, denotes the diameter which separates the size distribution by number so that $95 \%$ of the drops are smaller while the other $5 \%$ are bigger than $d_{\mathrm{N} 95}$. Similarly, the maximal diameter by volume, $d_{\mathrm{V} 95}$, presents the diameter of drops for which $95 \%$ of the whole dispersed oil in the sample is included in drops with diameter smaller than $d_{\mathrm{v} 95}$. Analogously, the mean diameters by number and by volume, $d_{\mathrm{N} 50}$ and $d_{\mathrm{V} 50}$ denote the diameters which divide $50 \%$ of the drops to be below and above the respective diameter.

\subsection{Interfacial tension measurements.}

The alkane-water interfacial tension, $\gamma$, was measured by drop-shape analysis at different temperatures. ${ }^{39,40}$ The shape of millimeter sized pendant oil drops, immersed in the surfactant solution, was recorded and analyzed by the Laplace equation of capillarity (instrument DSA100 by Krüss, Germany). The thermostatic cell TC40 was used to vary the temperature of the measured system with a precision of $\pm 0.2^{\circ} \mathrm{C}$.

In a typical experiment, the temperature was decreased with a rate mimicking that in the actual experiments with slowly cooled emulsions (between 0.1 and $0.5 \mathrm{~K} / \mathrm{min}$ ). In separate experiments, the actual temperature at the position of the pendant drop was measured by a calibrated thermocouple. Also, for some of the systems a discrete set of decreasing temperatures was used, with equilibration of 15 or $60 \mathrm{~min}$ at each temperature. For a given temperature, the 
interfacial tensions measured at a constant cooling rate and at fixed temperature were in agreement, with the tension measured at constant temperature being the same or only slightly lower (within $0.5 \mathrm{mN} / \mathrm{m}$ ), as very slow rearrangement of the molecules may take place in the frozen adsorption layers. The latter difference was observed at the lowest temperatures only, while the deformation of the emulsified drop in the same solution had already started at higher temperatures.

These different regimes of cooling were used to check for possible effects of the finite time required for the temperature at the drop center to equilibrate. One can estimate this time from the laws of heat-diffusion in a spherical body. ${ }^{41}$ These estimates show that the relaxation of the temperature difference from the surface to the center of spherical drops with diameter of $40 \mu \mathrm{m}$, like the bigger drops present in the studied emulsions, occurs for around $5 \mathrm{~ms}$ :

$$
\tau \approx \frac{d^{2}}{4 \chi}=\frac{(40 \mu \mathrm{m})^{2}}{3.2 \times 10^{-7}}=5 \mathrm{~ms}
$$

Here $\chi=\left(\kappa / \rho C_{\mathrm{p}}\right)$ is the thermal diffusivity of the dispersed phase, while $\kappa, \rho$, and $C_{\mathrm{p}}$, are its thermal conductivity, mass density and heat capacity. For the millimeter size pendant drops used to measure the oil-water interfacial tension, this relaxation time is of the order of several seconds.

As clarified from the obtained experimental results and from the above estimates, the cooling rates were sufficiently low to avoid complications related to possible difference in the temperatures at the surface and in the body of the studied drops. As the experiments at constant cooling rate mimic better the actual experiments with cooled emulsions, we show these data for the interfacial tension in Figure 8 below.

\section{Results and discussion}

In this section we present our experimental results about the self-emulsification phenomena and discuss the effects of the main factors: alkane chain-length, surfactant type, initial drop size and cooling rate. First we describe the process of drop bursting, observed upon emulsion cooling (Mechanism 1). Then we discuss the two mechanisms observed upon emulsion heating capillary instability of the melting fibers (Mechanism 2) and melt-crystal fragmentation of the platelets (Mechanism 3). Next, we compare the effectiveness of the different mechanisms and, on this basis, we discuss the results obtained with various systems and the possible approaches for control of the drop-size distribution. 


\subsection{Droplets bursting upon cooling (Mechanism 1)}

Oil-in-water emulsion drops, stabilized by appropriate surfactants, spontaneously change their shape upon cooling, as described in Introduction. An additional process is observed in some of the emulsions, namely drop bursting into smaller drops, as shown in Figure 2. In this process, single emulsion drop spontaneously breaks into several (between 2 and 15) daughter droplets. Drop bursting can be observed in all evolutionary stages in which the drop acquires a platelet shape. This excludes the last stages of the evolutionary scheme in which the drops undergo capillary instability to become ellipsoidal in shape and extrude thin fibers, as well as the "rodlike" stage in which cylindrical rods with uniform thickness are formed, cf. Figure 1. After drop bursting, the newly formed drops start to change their shape again and another bursting event can be observed. To quantify this bursting sequence, we count the number of the consecutive bursting events of the biggest "daughter" drops, formed after each breakage event.

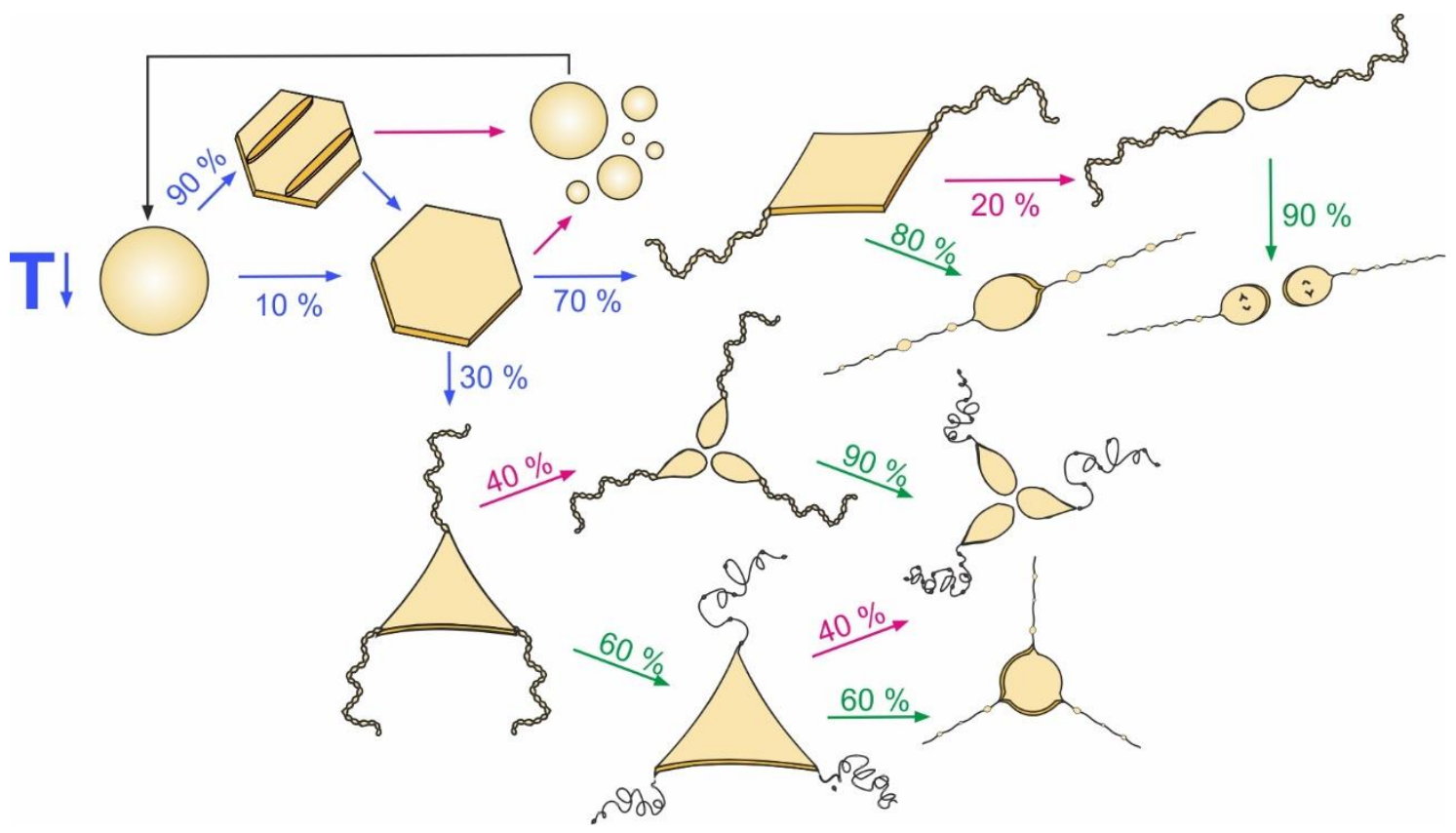

Figure 2. Scheme of drop-shape evolution, including the possible drop bursting processes upon cooling. Emulsion drops stabilized by long-chain surfactants change spontaneously their shape upon cooling. Along this drop shape evolution, bursting processes may be observed in which 2 to more than 10 "daughter" droplets are formed. Arrows in blue show the deformation processes, arrows in green - the process of capillary instability, and arrows in purple - the drop bursting processes. The probabilities, shown with numbers on the scheme, are observed with $\mathrm{C}_{17}$ drops with initial drop diameter, $d_{\text {ini }} \approx 34 \mu \mathrm{m}$, stabilized by $\mathrm{C}_{18} \mathrm{EO}_{20}$. No probabilities are associated with the arrows related to the puncture of the hexagonal platelets (top left), because this puncture was $100 \%$ in the first several drop bursting events and decreased to zero as smaller droplets were formed in this drop breakage process (see text for further explanations). 
Two distinct versions of this mechanism are observed. They are considered separately below, as the outcome of the bursting process and the effects of the various factors are different.

\section{Mechanism 1a-drop bursting via platelet central puncturing}

This mechanism was first described in our previous paper. ${ }^{19}$ Briefly, upon cooling, the platelet expands in area with time, because the frame of rotator phase gradually "sucks" molecules from the liquid interior of the platelet. Since the volume of the platelet is fixed, the platelet may eventually become thinnest in its central region, as shown in Figures $1 \mathbf{B}$ and $\mathbf{3 A}$. Thus, a thin water-oil-water film is formed in the platelet central region (Figure 3F,I) which is unstable for some surfactant-alkane pairs and punctures. The platelet puncture leads to formation of a toroidal in shape drop, which is capillary unstable and instantly breaks into several daughter droplets.

This bursting mechanism requires the formation of a platelet which retains its shape for a sufficiently long time to thin and form unstable water-oil-water film in its central region. This mechanism can be observed at any of the platelet stages of drop evolution - with hexagonal, tetragonal or trigonal platelets. The platelets extruding fibers can also burst as shown in Figure 3B-D.

Depending on the platelet shape, 2 (from tetragonal platelets) to 6 (from hexagonal platelets, Figure 3G) daughter droplets with comparable diameters are formed. The newly formed droplets have diameters between $0.5 d_{\text {ini }}$ and $0.8 d_{\text {ini }}$, where $d_{\text {ini }}$ is the radius of the initial spherical drop before its bursting. This mechanism is very effective for decreasing the size of the biggest droplets in the emulsion, characterized by $d_{\mathrm{V} 95}$ and $d_{32}$. On the other hand, this mechanism is ineffective for decreasing $d_{\mathrm{N} 95}$ and $d_{\mathrm{N} 50}$, because very limited number of much smaller droplets (most often none, sometimes 1 or 2 ) with diameter $d \leq 0.1 d_{\text {ini }}$, are formed. 

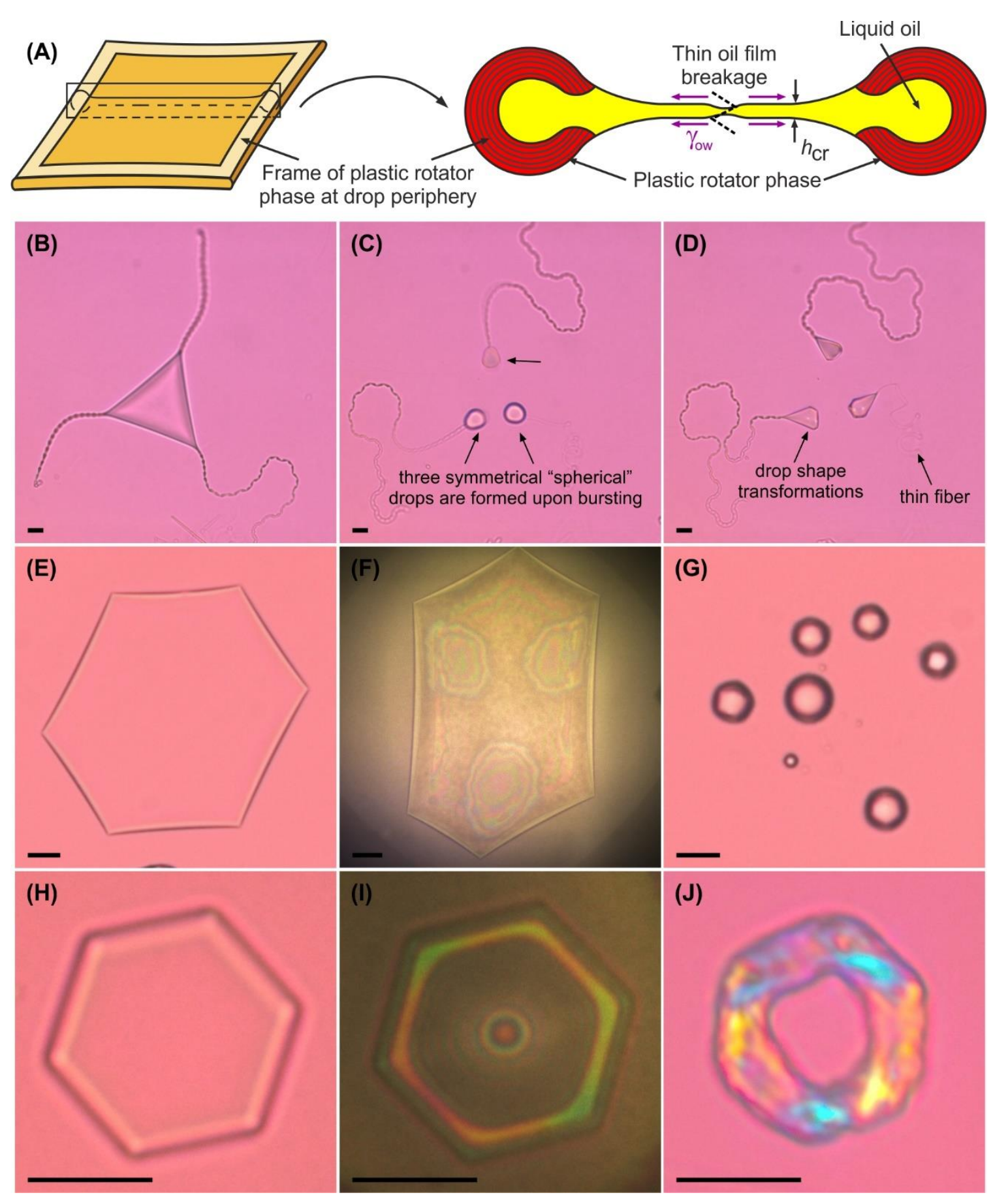

Figure 3. Drop bursting upon cooling via platelet puncture (Mechanism 1a). (A) The cooled platelets may acquire thinnest central region (thin water-oil-water film) which is unstable and breaks. The formed toroidal drop is capillary unstable and bursts into several smaller drops. (BD) Microscope images of a triangular platelet with protrusions which breaks in its center. (B) Platelet before bursting. (C) Three symmetrical daughter drops are formed after bursting which immediately (D) start to change their shape. (E-G) Hexagonal platelet which breaks in its center observed in (E) transmitted polarized light and (F) reflected light; $(\mathrm{G})$ daughter drops formed after the platelet breakage. (H-J) Microscope images of a hexagonal platelet with thin water-oilwater film in its center, observed in $(\mathrm{H})$ transmitted polarized light, (I) reflected light - the thin oil film is seen in the platelet center, $(\mathrm{J})$ transmitted polarized light after freezing - a hole in the platelet center is formed due to the film breakage upon freezing. Scale bars, $10 \mu \mathrm{m}$. Experiments performed with $\mathrm{C}_{16}$ oil drops stabilized by $\mathrm{C}_{18} \mathrm{EO}_{20}(\mathrm{~B}-\mathrm{G})$ or $\mathrm{C}_{16} \mathrm{EO}_{2}(\mathrm{H}-\mathrm{J})$ surfactants. 


\section{Mechanism $1 b$-drop bursting due to breakage of the platelet plastic frame}

The second mechanism of drop bursting upon cooling is again caused by platelet puncture. However, in this case it is triggered by a mechanical breakage of one or several of the rods from the expanding plastic frame at the drop perimeter, which on its turn leads to a local thinning and rupture of the platelet near the broken plastic rod.

In our previous study we showed that depending on the particular oil-surfactant combination used, the thickness and the strength of the plastic rods of rotator phase, formed at the drop perimeter is different. ${ }^{21}$ For example, we found that $\mathrm{C}_{16}$ drops stabilized by $\mathrm{C}_{18} \mathrm{EO}_{20}$, form thinner and more flexible rotator phase, as compared to those stabilized by $\mathrm{C}_{18} \mathrm{SorbEO}_{20}$. Our observations showed that these rods of thinner rotator phase might be not strong enough to withstand the stress created by the oil-water interfacial tension, which compresses the frame toward the platelet center. As a result, the frame of plastic rods may break, as shown in Figure 4. After such breakage, the broken rod bends towards the platelet center, under the action of the interfacial tension (Figure 4B), the oil film gets corrugated locally around the broken rod, and a platelet breakage can occur via puncture at some thin local spot in the corrugated region (Figure 4C).

Another type of mechanical instability of the plastic frame and subsequent platelet breakage was also observed. It occurs close to one of the platelet vertices. The two sides forming a vertex start to bend towards the platelet center, again creating local corrugations of the platelet surfaces, followed by platelet puncturing and bursting close to the vertex, see Figure 4G-I. Mechanism $1 b$ occurs more often via such vertex breakage event, in the process of polyhedrons flattening into a platelet.

Mechanism $1 b$ may be observed also in the process of transformation of the polyhedrons into platelets via wrinkle formation, see the lower branch in Figure 1A. When the cooling rate is higher than $1 \mathrm{~K} / \mathrm{min}$, irregular polyhedrons are formed in the initial stage of drop evolution in many of the emulsions studied. These wrinkles consume a large fraction of the oil inside the drops and their dynamics creates mechanical stresses in the deformed drops. Drop bursting via puncturing of the flattened regions between the wrinkles in the deformed drops may occur in this stage of drop evolution as well, see Movie 1. 


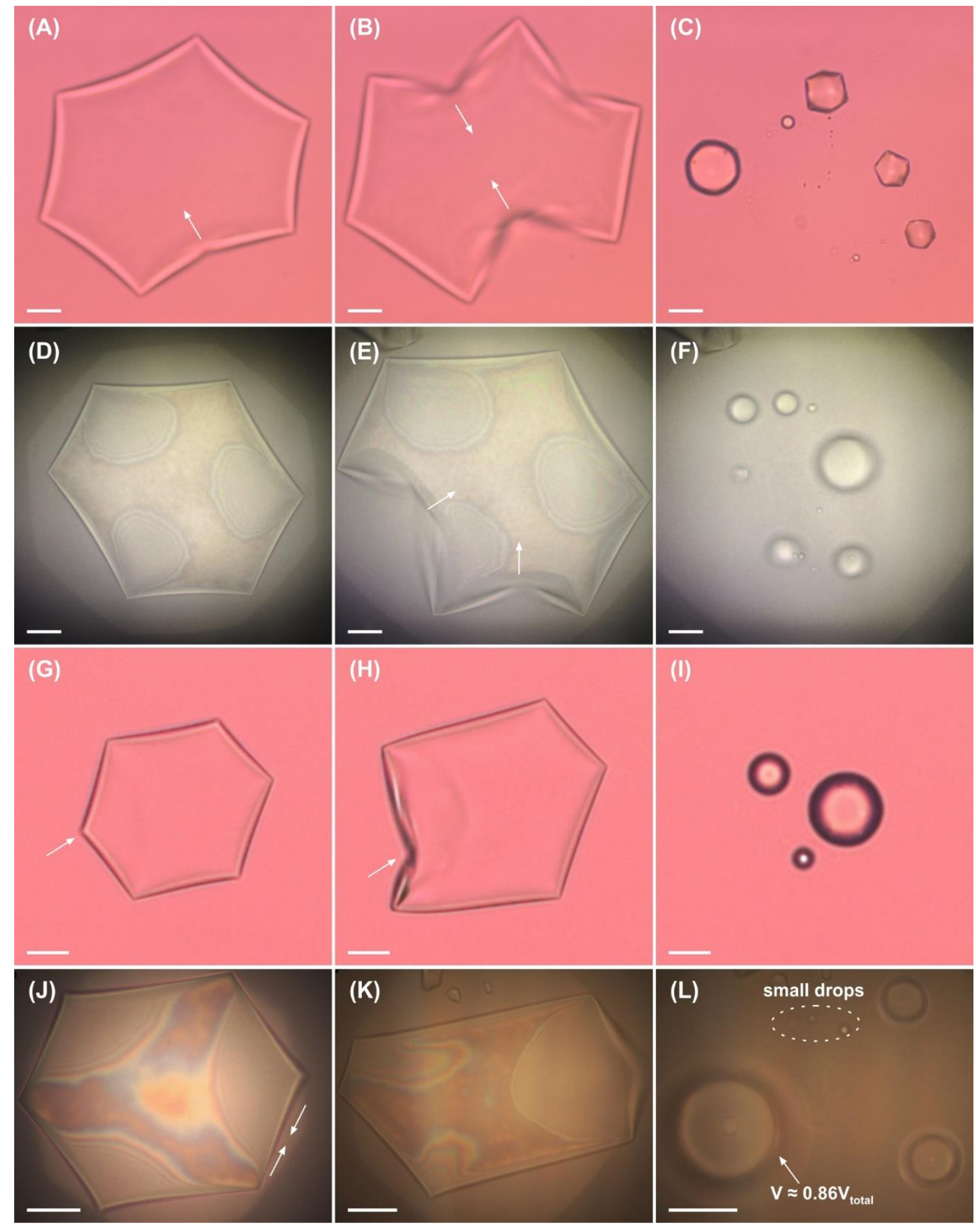

Figure 4. Drop bursting upon cooling via rotator phase breakage and puncturing (Mechanism 1b). (A-F) Upon cooling platelets which thin symmetrically may exhibit breakage of the rotator phase frame (B, E). As a result, the oil film thins locally and breaks (C, F). (G-L) Platelets may thin asymmetrically and breakage of the rotator phase near the platelet tip may occur, resulting in platelet puncturing. All experiments are performed with $\mathrm{C}_{16}$ drops, stabilized by $\mathrm{C}_{18} \mathrm{EO}_{20}$ surfactant. Pictures in (A-C) and (G-I) are made in transmitted polarized light, while these in (D-F) and (J-L) in reflected white light. Scale bars, $20 \mu \mathrm{m}$. 
The newly formed daughter drops are in much larger number when they are formed via Mechanism 1b, as compared to Mechanism la. Often more than 10 droplets are formed in Mechanism $1 b$, while this number is usually between 2 and 6 in Mechanism $1 a$. On the other hand, because the drop breakage is asymmetric in Mechanism $1 b$, the newly formed droplets are polydisperse. Usually, one or two big drops are formed, containing more than $90 \%$ of the oil volume, while the other formed drops are much smaller. Therefore, this mechanism is not so effective in reducing $d_{32}$, but it is more effective than Mechanism 1a for reducing $d_{\mathrm{N} 95}$ and $d_{\mathrm{N} 50}$, due to the formation of numerous small droplets.

Let us discuss now the effects of the alkane chain length, surfactant type, initial drop size, and cooling rate on this mechanism.

\section{Effect of alkane chain length on drop bursting upon cooling}

In our previous study, we found that one of the most efficient surfactants for selfemulsification is $\mathrm{C}_{18} \mathrm{EO}_{20}{ }^{19}$ Therefore, first we discuss the behavior of drops from different alkanes (chain-length varied between 14 and $20 \mathrm{C}$-atoms) with the same initial drop size, $d_{\text {ini }} \approx$ $34 \mu \mathrm{m}$, stabilized by $\mathrm{C}_{18} \mathrm{EO}_{20}$ and cooled at $0.2 \mathrm{~K} / \mathrm{min}$.

For the longest chain-length alkanes studied, nonadecane and eicosane $\left(\mathrm{C}_{19}\right.$ and $\left.\mathrm{C}_{20}\right)$, bursting events are not observed upon cooling, as seen from the results summarized in Table 1. The drops evolve up to the platelet stage, see Figure 5A-C, but without platelet bursting being observed.

When the same experiment is performed with shorter alkane, $\mathrm{C}_{18}$, the drop transformations are easier and some breakage events (between 0 and 2) are observed via both Mechanisms la and $1 b$.

The maximal number of breakage events for $\mathrm{C}_{18} \mathrm{EO}_{20}$ surfactant is observed when alkanes with slightly shorter chain-length are used, $\mathrm{C}_{17}$ and $\mathrm{C}_{16}$. For these alkanes, the drop shape transformations are quite easy; the formed plastic rods are thin and fragile and, as a result, they break easily. Between 1 and more than 10 consecutive breakage events are observed for a single drop in these systems. Although the behavior of $\mathrm{C}_{16}$ and $\mathrm{C}_{17}$ drops is qualitatively similar, the number of bursting events for $\mathrm{C}_{17}$ is larger (typically 7 or 8 , up to more than 15 ) as compared to those with $\mathrm{C}_{16}$ (typically, one to several). This difference can be explained with the preferred shape of the deformed droplets - the $\mathrm{C}_{17}$ drops become very flat hexagonal platelets before they pass into the next stages of the evolutionary scheme, while the $\mathrm{C}_{16}$ drops pass rapidly into the subsequent stages in which thin fibers are extruded, thus reducing the probability for platelet puncture. 
When shorter alkanes are used, $\mathrm{C}_{14}$ and $\mathrm{C}_{15}$, the number of breakage events decreases further, due to the even faster platelet transformation into the shapes in which thin fibers are extruded, without passing through the stage of flattened platelets with thinner central region. No drop breakages via Mechanism $1 a$ are observed with $\mathrm{C}_{14}$ and $\mathrm{C}_{15}$ oils, see Figure 5I-K.

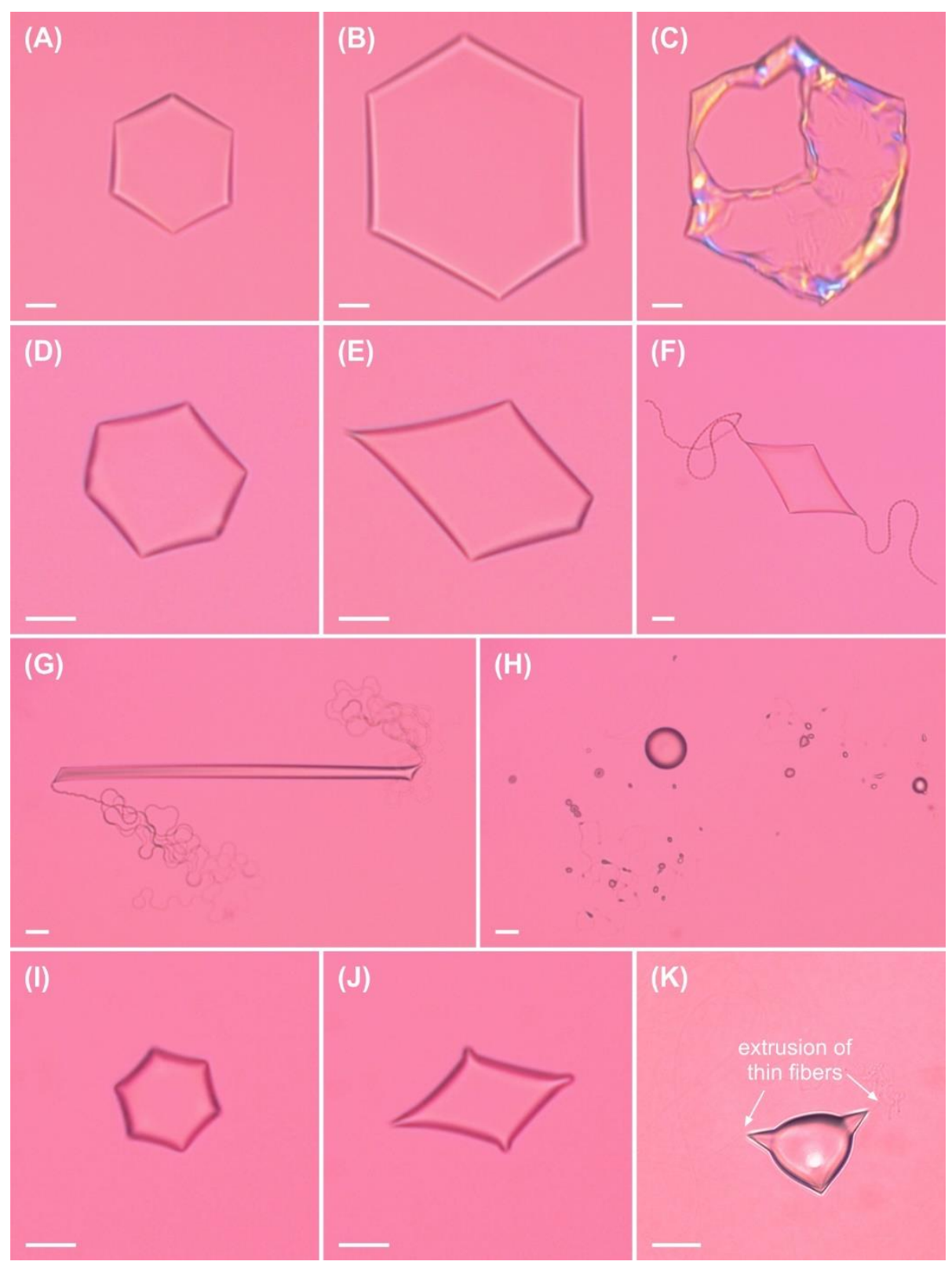

Figure 5. Microscope images showing platelet formation and fiber extrusion for different alkanes. (A-C) $\mathrm{C}_{19}$ drops, stabilized by $\mathrm{C}_{18} \mathrm{EO}_{20}$. Upon cooling, these drops deform into thin hexagonal platelets and freeze without passing into the next stages of the evolutionary scheme. (D-H) $\mathrm{C}_{16}$ drops, stabilized by $\mathrm{C}_{18} \mathrm{EO}_{20}$. These drops form thin platelets prior to fiber extrusion. The rod-like $(\mathrm{G})$ and capillary instability stages $(\mathrm{H})$ are passed before these drops become ellipsoidal and start extruding thin fibers. (I-K) $\mathrm{C}_{14}$ drops, stabilized by $\mathrm{C}_{18} \mathrm{EO}_{20}$. Upon cooling, these drops pass from hexagonal into tetragonal platelets when they are still rather bulky (viz. with convex surface, instead of being thin flat platelets as in A-F). The drops start to extrude thin fibers almost immediately after acute corners are formed and ellipsoidal drops are formed soon afterwards, without passing through the stages of thin flat platelets and rods. 
The observed maximum in the number of bursting events, when varying the alkane chainlength, is preserved when other surfactants are used. For example, drops stabilized by $\mathrm{C}_{16} \mathrm{SorbEO}_{20}$ behave qualitatively similar to those stabilized with $\mathrm{C}_{18} \mathrm{EO}_{20}$. However, because $\mathrm{C}_{16}$ SorbEO $_{20}$ is by $2 \mathrm{C}$-atoms shorter, the $\mathrm{C}_{14} / \mathrm{C}_{16}$ SorbEO $_{20}$ system behaves similarly to $\mathrm{C}_{16} / \mathrm{C}_{18} \mathrm{EO}_{20}$, whereas $\mathrm{C}_{15} / \mathrm{C}_{16}$ SorbEO ${ }_{20}$ behaves similarly to $\mathrm{C}_{17} / \mathrm{C}_{18} \mathrm{EO}_{20}$. Drops, stabilized by $\mathrm{C}_{18}$ SorbEO$_{20}$ surfactant burst rarely, because a very thick frame of rotator phase is formed with $\mathrm{C}_{16}$ in this system (and this is the alkane for which one may expect the largest number of bursting events with this surfactant, due to their similar chain lengths).

\section{Effect of surfactant type for different alkanes}

In our previous study ${ }^{21}$, we classified the surfactants into four groups, with respect to their effect on drop-shape changes upon cooling. These groups are: Groups A-C - surfactants which induce self-shaping but the deformations starts at different temperatures, $T_{\mathrm{d}}$, as compared to the bulk melting temperature of the emulsified alkane, $T_{\mathrm{m}}$. For Group $A: T_{\mathrm{d}}>T_{\mathrm{m}}$; for Group B: $T_{\mathrm{d}} \approx$ $T_{\mathrm{m}}$; and for Group $C$ : $T_{\mathrm{d}}<T_{\mathrm{m}}$. Group $D$ contains surfactants which do not induce self-shaping, see Table 2.

Drop bursting via Mechanism 1 is observed mainly with surfactants from Group A. For drops, stabilized by these surfactants, we observed up to more than 10 consecutive breakage events, most typically between 2 and 8. Surfactants from Group B induce usually between 1 and 3 breakage events, while drop breakage with surfactants from Group $C$ is rarely observed.

Although all surfactants from Group A induce many breakage events, the behavior of the various systems is different. Drop shape transformations for $\mathrm{C}_{16}$ drops, stabilized by surfactants with 10 ethoxy groups $\left(\mathrm{C}_{16} \mathrm{EO}_{10}\right.$ and $\left.\mathrm{C}_{18} \mathrm{EO}_{10}\right)$, start at temperature $T_{\mathrm{d}} \approx T_{\mathrm{m}}+5^{\circ} \mathrm{C}$, viz. at $\Delta T=T_{\mathrm{d}}$ $-T_{\mathrm{m}} \approx 5^{\circ} \mathrm{C}$. The drops in these systems do not have a tendency to form platelets with thin filaments. Instead, irregular in shape (corrugated) platelets are formed during cooling, resulting in several breakage events in the process of platelet formation. After each of the bursting events, a small number (typically between 1 and 3) of much smaller droplets are formed and the main fraction of the oil remains in a single drop with diameter close to the initial one, see Movie $\mathbf{1 .}$ Thus, the mean volume-surface diameter, $d_{32}$, does not change significantly, while the number diameters $d_{\mathrm{N} 95}$ and $d_{\mathrm{N} 50}$ decrease notably. This behavior is observed with $\mathrm{C}_{16}$ drops, stabilized by the nonionic surfactants $\mathrm{C}_{16} \mathrm{EO}_{10}$ and $\mathrm{C}_{18} \mathrm{EO}_{10}$, and also with $\mathrm{C}_{18}$ drops, stabilized by the anionic surfactant $\mathrm{C}_{18} \mathrm{SO}_{4} \mathrm{Na}$.

The other surfactants from Group A, which tend to form platelets with thin filaments, typically at $\Delta T \approx 1-4^{\circ} \mathrm{C}$, lead to intensive drop breakage via both Mechanisms $1 a$ and $1 b$, with 
the formation of 2 to 6 drops of comparable diameter, plus several much smaller droplets. In this case, Mechanism 1 is most effective and even can be comparable in effectiveness to Mechanism 3 (melt-crystal fragmentation), discussed below. In this group we place $\mathrm{C}_{18} \mathrm{EO}_{20}$ surfactant with $\mathrm{C}_{16}$ and $\mathrm{C}_{17}$ alkanes, and $\mathrm{C}_{16}$ SorbEO$_{20}$ with $\mathrm{C}_{14}$ and $\mathrm{C}_{15}$ alkanes.

When the temperature difference $\Delta T$ is bigger than $5-6^{\circ} \mathrm{C}$, the formation of thin fibers is quite easy, and the drops start to extrude such fibers even from bulky shapes, without the formation of large flat platelets, see Figure 5I-K. The number of breakage events decreases down to 1-2 and they usually lead to the formation of one big drop and 1-2 small droplets. Hence, the decrease in $d_{32}$ is insignificant in these systems. This behavior is observed with $\mathrm{C}_{14}$ and $\mathrm{C}_{15}$ drops, stabilized by $\mathrm{C}_{18} \mathrm{EO}_{20}$ surfactant.

\section{Effect of the initial drop size}

Usually, the bigger drops with $d_{\text {ini }} \approx 20-30 \mu \mathrm{m}$ burst more often than the smaller ones, $d_{\text {ini }} \leq$ $10 \mu \mathrm{m}$. Furthermore, for $\mathrm{C}_{16}$ drops stabilized by $\mathrm{C}_{18} \mathrm{EO}_{20}$ surfactant, we observe a critical drop diameter, $d_{\mathrm{ini}} \approx 12 \mu \mathrm{m}$, below which the drops do not burst anymore. In this system, drops with diameter around $15 \mu \mathrm{m}$ bursts usually only once, while $34 \mu \mathrm{m}$ drops burst between 1 and 6 times (most often 2 or 3 ) when cooled at $1.4 \mathrm{~K} / \mathrm{min}$. This trend is explained by considering the kinetics of drop shape evolution and its dependence on $d_{\text {ini. }}$. The small drops always evolve faster to the last stages of the evolutionary scheme, thus passing quicker through the platelet stages. ${ }^{21}$ Therefore, the platelets formed from such small drops do not have enough time to thin and burst via Mechanism $1 a$ or $1 b$. Once the drops are in the last stage of the evolutionary scheme, they cannot burst via Mechanism 1, except in the case of triangular platelets, as already discussed.

In some rare systems we observe the opposite dependence on drop size which could be also explained with the kinetics of drop shape transformations. For example, as explained in section Effect of alkane chain length above, it is more difficult for $\mathrm{C}_{17}$ drops to evolve into the stage of thin fiber extrusion. Hence, the small drops with diameters below $10 \mu \mathrm{m}$ burst as platelets between 4 and 10 times in this system when cooled at $1.4 \mathrm{~K} / \mathrm{min}$, while the bigger drops with $d_{\text {ini }}$ $\approx 34 \mu \mathrm{m}$ evolve much more slowly and burst around 3-4 times only, before they freeze.

\section{Effect of the cooling rate}

The cooling rate influences the number of bursting events in Mechanism 1 in two different ways. The number of bursting events via Mechanism $1 a$ is decreased at higher cooling rate because the time available for making a thin film in the center of a regular platelet (needed for effectuation of this mechanism) is shorter. On the contrary, when Mechanism $1 b$ occurs via 
wrinkle formation in the process of platelet formation, the higher cooling rate leads to larger number of bursting events, because more dynamic wrinkles are formed. As examples of these trends, $\mathrm{C}_{17}$ drops with $d_{\text {ini }} \approx 34 \mu \mathrm{m}$, stabilized by $\mathrm{C}_{18} \mathrm{EO}_{20}$, burst more times when cooled at low cooling rate (via Mechanism 1a), while the $\mathrm{C}_{16}$ drops, stabilized by the same surfactant, burst more times when cooled at higher cooling rate (via Mechanism 1b).

In conclusion, Mechanism 1 is most effective to decrease $d_{32}$ when the breakage occurs via film thinning and breakage in the platelet center (Mechanism 1a) because 2 to 6 similar in size drops are formed in this case. This behavior is observed with oil-surfactants pairs for which $\Delta T \approx$ $2-3^{\circ} \mathrm{C}$ and the drops have the tendency to form platelets, protruding thin filaments. All main experimental trends can be explained by considering the effect of the observed drop shape kinetics on the probability for realization of Mechanism $1 a$ or Mechanism $1 b$.

\subsection{Capillary instability of long fibers (Mechanism 2)}

The second mechanism of self-emulsification consists of two stages: Stage 1 - capillary instability of a platelet or rod (Mechanism 2a) or fiber extrusion (Mechanism 2b) during cooling, and Stage 2 - disintegration of the melting fibers which are pre-formed in Stage 1.

\section{Stage 1 in Mechanism 2}

Mechanism 2a: Upon cooling, capillary instability is observed in the final stages of the evolutionary scheme. In this process the bulk of the alkane in the shaped droplet re-forms (from a platelet or rod) into one or several ellipsoidal drops with several sharp conical tips from which thin fibers are extruded, see Figures 1A and 2. Usually, after this event, the whole oil drop reforms into a single ellipsoidal drop, see Figure 5D-H. However, in some cases two or three drops with comparable size have been also observed to form, see Figure 6A-D. The latter event is observed mainly with systems forming intermediate and thick rotator phases, i.e. with surfactants from Groups $B$ and $C$, according to the classification in Table 2. Upon cooling, these drops are connected to one another via very thin fibers with diameter $<1 \mu \mathrm{m}$. If these samples are heated slowly, prior to the final drop freezing, these apparently separated drops coalesce back and re-form the single oil drop, from which they had been obtained, see Movie 2. However, after freezing and upon subsequent melting, the thin fibers disintegrate into numerous small droplets, as described below, in section Stage 2 in Mechanism 2. Respectively, the big ellipsoidal drops become truly separated after melting, reducing the drop volume by 2 to 3 times and the drop diameter - by 20 to $30 \%$.

Mechanism 2b: Along the drop shape evolution, upon cooling, thin fibers with diameter between ca. 0.5 and $5 \mu \mathrm{m}$ protrude from the platelet corners in many of the evolutionary stages, see Figure 1A and Figure 6E,H. These fibers are stable upon cooling and freezing, due to the elasto-plastic rigidity of the rotator phase. However, they break upon melting as described below. 


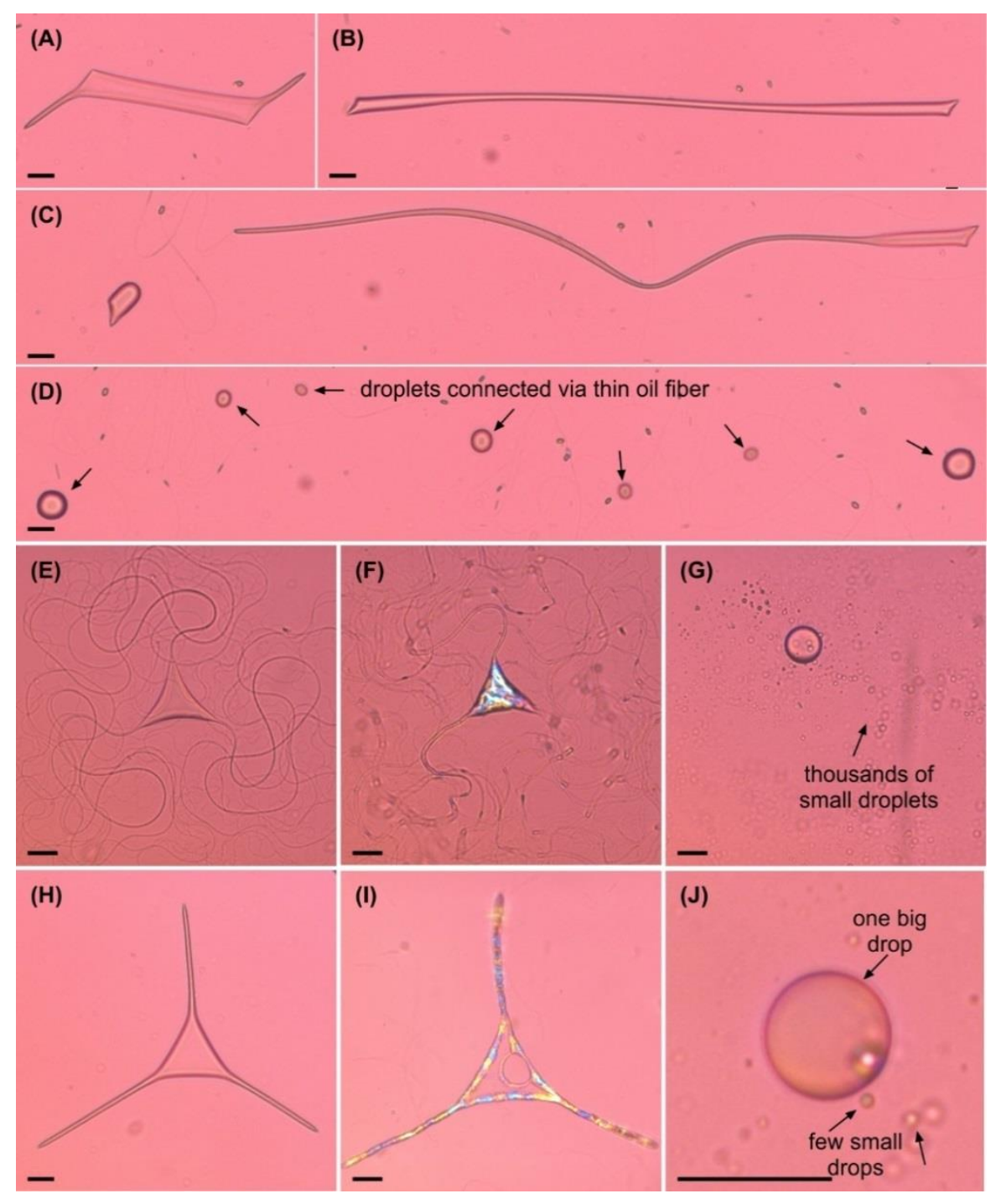

Figure 6. Capillary instability of long fibers (Mechanism 2). (A-D) Upon slow cooling, the drops may undergo a process of capillary instability in which the main fraction of the oil reforms into one or several ellipsoidal drops, connected to one another with thin fibers. (A) Elongating tetragonal prism. (B-C) Capillary instability. (D) Drops formed after the capillary instability has occurred. Experiment with $\mathrm{C}_{16}$ drop, stabilized by $\mathrm{C}_{16} \mathrm{EO}_{20}$. (E-J) The fibers, extruded upon cooling, are stabilized by the elasto-plastic properties of the rotator phase. However, upon melting they break into numerous small droplets via hydrodynamic instability of RayleighPlateau type. (E-G) Breakage observed with fibers of diameter $\approx 2 \mu \mathrm{m} . \mathrm{C}_{15}$ drop, stabilized by $\mathrm{C}_{16} \mathrm{EO}_{20}$. (H-J) Fibers with diameter $\approx 4 \mu \mathrm{m}$ do not disintegrate upon melting. From this triangular platelet with protrusions, one big drop and several small droplets are formed. $\mathrm{C}_{16}$ drop, stabilized by $\mathrm{C}_{16} \mathrm{EO}_{20}$. Scale bars, $20 \mu \mathrm{m}$. 
Table 1. Frequency of occurrence of the different mechanisms for the 4 main nonionic surfactants studied, in combination with alkanes of different chain-lengths. The sign "_" denotes that the respective mechanism is not observed with this system. Plus signs denote the frequency and/or intensity of observation. One "+" sign denotes that this mechanism is observed for less than 50\% of the drops and/or the mechanism is not very effective. Two "++" signs denote that the mechanism is observed for more than $80 \%$ of the drops and triple "+++" sign denotes that the mechanism is observed for all drops. In addition, for Mechanisms 1, "+" sign denotes that up to 3 consecutive breakage events, "++" sign - up to 6 consecutive breakage events, and "+++" sign - more than 6 consecutive breakage events are observed. See the text for detailed explanations about the different mechanisms.

\begin{tabular}{|c|c|c|c|c|c|c|}
\hline \multirow{2}{*}{ Surfactant } & \multirow{2}{*}{ Alkane } & \multicolumn{2}{|c|}{ Drop bursting upon cooling } & \multicolumn{2}{|c|}{ Disintegration of thin fibers } & \multirow{2}{*}{$\begin{array}{c}\text { Melt-crystal fragmentation } \\
\text { Mechanism } 3\end{array}$} \\
\hline & & Mechanism 1a & Mechanism $1 b$ & Mechanism $2 a$ & Mechanism $2 b$ & \\
\hline \multirow{4}{*}{$\mathrm{C}_{16} \mathrm{EO}_{20}$} & $\mathrm{C}_{14}$ & 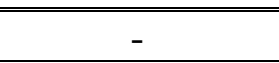 & - & + & +++ & - \\
\hline & $\mathbf{C}_{15}$ & - & - & ++ & +++ & - \\
\hline & $\mathrm{C}_{16}$ & - & - & +++ & ++ & + \\
\hline & $\mathbf{C}_{\mathbf{1 7}}$ and longer & - & - & - & - & - \\
\hline \multirow{7}{*}{$\mathrm{C}_{18} \mathrm{EO}_{20}$} & $\mathrm{C}_{14}$ & - & + & - & ++++ & - \\
\hline & $\mathrm{C}_{15}$ & - & + & + & +++ & + \\
\hline & $\mathrm{C}_{16}$ & + & ++ & ++ & +++ & +++ \\
\hline & $\mathbf{C}_{17}$ & +++ & +++ & +++ & +++ & +++ \\
\hline & $\mathrm{C}_{18}$ & + & + & - & - & +++ \\
\hline & $\mathrm{C}_{19}$ & - & - & - & - & ++ \\
\hline & $\mathbf{C}_{20}$ and longer & - & - & - & - & - \\
\hline \multirow{4}{*}{$\mathrm{C}_{16} \operatorname{SorbEO}_{20}$} & $\mathrm{C}_{14}$ & + & ++++ & ++++ & ++++ & - \\
\hline & $\mathrm{C}_{15}$ & +++ & + & ++ & +++ & +++ \\
\hline & $\mathrm{C}_{16}$ & - & + & - & - & + \\
\hline & $\mathbf{C}_{\mathbf{1 7}}$ and longer & - & - & - & - & - \\
\hline \multirow{4}{*}{$\mathrm{C}_{18}$SOrbEO$_{20}$} & $\mathrm{C}_{14}$ & 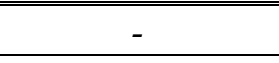 & + & +++ & +++ & - \\
\hline & $\mathrm{C}_{15}$ & + & - & ++ & +++ & + \\
\hline & $\mathrm{C}_{16}$ & - & + & - & - & + \\
\hline & $\mathbf{C}_{\mathbf{1 7}}$ and longer & - & - & - & - & - \\
\hline
\end{tabular}


Table 2. Surfactant classification with respect to the temperature, $T_{\mathrm{d}}$, at which the first drop deformation is observed (see also ref. 21 ).

\begin{tabular}{|c|c|c|c|c|c|}
\hline & $\begin{array}{c}\text { Drop shape } \\
\text { transformations } \\
\text { upon cooling }\end{array}$ & $\begin{array}{c}\text { Deformation temperature, } T_{\mathrm{d}} \text {, } \\
\text { compared to bulk melting } \\
\text { temperature, } T_{\mathrm{m}}\end{array}$ & $\begin{array}{c}\text { Interfacial layers' } \\
\text { strength } \\
\text { (thickness) }\end{array}$ & $\begin{array}{c}\text { Typical number of } \\
\text { breakage events in } \\
\text { Mechanism } 1\end{array}$ & $\begin{array}{l}\text { Surfactants in this } \\
\text { group for } \mathrm{C}_{16} \text { alkan }\end{array}$ \\
\hline Group A & Yes & $T_{\mathrm{d}}>T_{\mathrm{m}}$ & $\begin{array}{c}\text { thin flexible layers } \\
\text { and rods }\end{array}$ & $1-10$ & $\begin{array}{l}\mathrm{C}_{16} \mathrm{EO}_{10} \\
\mathrm{C}_{18} \mathrm{EO}_{10} \\
\mathrm{C}_{18} \mathrm{EO}_{20}\end{array}$ \\
\hline Group B & Yes & $T_{\mathrm{d}} \approx T_{\mathrm{m}}$ & $\begin{array}{l}\text { very strong (thick) } \\
\text { layers and rods }\end{array}$ & $1-3$ & $\begin{array}{l}\mathrm{C}_{16} \mathrm{SorbEO}_{20} \\
\mathrm{C}_{18} \mathrm{SorbEO}_{20}\end{array}$ \\
\hline Group C & Yes & $T_{\mathrm{d}}<T_{\mathrm{m}}$ & $\begin{array}{l}\text { Intermediate, soft } \\
\text { layers and rods }\end{array}$ & - & $\begin{array}{c}\mathrm{C}_{16} \mathrm{EO}_{20} \\
\mathrm{C}_{16-18} \mathrm{EO}_{25} \\
\mathrm{C}_{16} \mathrm{TAB}\end{array}$ \\
\hline Group D & No & - & - & - & $\begin{array}{c}\mathrm{C}_{12} \mathrm{EO}_{23} \\
\mathrm{C}_{12} \mathrm{SorbEO}_{20} \\
\mathrm{C}_{20-40} \mathrm{EO}_{50}\end{array}$ \\
\hline
\end{tabular}




\section{Stage 2 in Mechanism 2}

Upon melting, the fibers formed in Stage 1 split into numerous small droplets with diameter around two times bigger than the fiber diameter. These observations evidence that the cylindrical fibers disintegrate in the moment of oil melting, as a result of hydrodynamic instability of Rayleigh-Plateau type, Supplementary Figure S2. ${ }^{19}$

This stage is operative only for fibers with diameter around or below $2.5 \mu \mathrm{m}$. From such fibers, hundreds of small drops are formed upon melting. For example, if a fiber is $1000 \mu \mathrm{m}$ long and has a radius, $R_{\mathrm{f}} \approx 0.5 \mu \mathrm{m}$, and the radius of the formed drops is, $R_{\mathrm{d}} \approx 2 R_{\mathrm{f}}$, the number of the newly formed droplets is estimated to be $>200$, just from this single fiber (most of the drops extrude usually two or three fibers which may be much longer than the length used for this estimate). Thus, hundreds or thousands of small droplets are formed from one oil drop after just one freeze-thaw cycle, see Figure 6E-G. In contrast, the thicker fibers melt slowly and are able to reform back into a single drop, as shown on Figure 6H-J with $\mathrm{C}_{16}$ drops, stabilized by $\mathrm{C}_{16} \mathrm{EO}_{20}$.

This mechanism is extremely operative for reducing $d_{\mathrm{N} 95}$ and $d_{\mathrm{N} 50}$, making them around and below $1 \mu \mathrm{m}$, after only one freeze-thaw cycle for the systems in which Mechanism $2 b$ is operative, see Table 1. It is also effective for reducing $d_{32}$ when Mechanism $2 a$ is operative, see Table 1 and Discussion section below.

\section{Effect of alkane chain length}

Mechanism 2 is most effective when the drops evolve up to the final stages of the evolutionary scheme before freezing. Thus, alkane molecules which are shorter than the surfactant tail-length are most prone to be involved in Mechanism 2. The systems for which Mechanism $2 b$ is most pronounced include $\mathrm{C}_{14}, \mathrm{C}_{15}, \mathrm{C}_{16}, \mathrm{C}_{17}$ emulsions, stabilized by $\mathrm{C}_{18} \mathrm{EO}_{20}$ or $\mathrm{C}_{18} \mathrm{SO}_{4} \mathrm{Na} ; \mathrm{C}_{14}$ and $\mathrm{C}_{15}$ emulsions, stabilized by $\mathrm{C}_{16} \mathrm{SorbEO}_{20}$ or $\mathrm{C}_{18} \mathrm{SorbEO}_{20} ; \mathrm{C}_{14}, \mathrm{C}_{15}$ and $\mathrm{C}_{16}$ emulsions, stabilized by $\mathrm{C}_{16} \mathrm{EO}_{20}$; and $\mathrm{C}_{14}$ emulsions, stabilized by $\mathrm{C}_{16} \mathrm{TAB}$. With all these systems, intensive fiber formation is observed if slow cooling rate and appropriate initial drop size are used.

The effectiveness of Mechanism $2 a$ depends also on the thickness of the rotator phase formed on the drop surface. For example, the rotator phase is very fragile in the $\mathrm{C}_{14}+\mathrm{C}_{18} \mathrm{EO}_{20}$ emulsion and the drops start extruding fibers even from bulky shapes, without passing through the capillary instability stage, as it would be the case with $\mathrm{C}_{16}$. Thus, Mechanism $2 b$ is operative in $\mathrm{C}_{14}+\mathrm{C}_{18} \mathrm{EO}_{20}$ emulsion, while Mechanism $2 a$ is not observed in this system. In contrast, if $\mathrm{C}_{14}$ is used with sorbitan surfactants, the drops evolve up to the final stages of the evolutionary scheme, passing through the capillary instability stage and both Mechanisms $2 a$ and $2 b$ are observed.

\section{Effect of surfactant type}

For $\mathrm{C}_{16}$ alkane, the drops with $d_{\text {ini }} \approx 34 \mu \mathrm{m}$, stabilized by sorbitan surfactants (from Group B), evolve only up to the flat platelet stage and Mechanism 2 is not operative. In 
contrast, $\mathrm{C}_{16}$ emulsions, stabilized by surfactants from Group $A$ and $C$, can evolve up to the final stages of the evolutionary scheme - respectively, Mechanism 2 is active upon heating. As already explained, when shorter alkanes are used $\left(\mathrm{C}_{14}\right.$ or $\left.\mathrm{C}_{15}\right)$, the surfactants from Group $B$ (as classified for $\mathrm{C}_{16}$ ) can form thinner rotator phases and, respectively the drops in these emulsions may evolve into the final stages of the evolutionary scheme. Respectively, drop disintegration via Mechanism 2 is observed upon subsequent heating with such short-chain alkanes, even with Sorbitan surfactants, see Table 1.

\section{Effect of the initial drop size and cooling rate}

The drops with smaller initial diameter and cooled at lower rates evolve up to the further stages of the evolutionary scheme. Therefore, these drops are more likely to extrude fibers and to undergo capillary instability upon cooling. Respectively, upon heating after freezing, the fibers with diameter less than $2.5 \mu \mathrm{m}$ disintegrate in such systems, forming numerous small droplets.

In conclusion, Mechanism 2 is most operative for emulsions in which the chain length of the oil is slightly shorter than the chain length of the surfactant tail, because the drops in these systems usually evolve to the final stages of the evolutionary scheme. Mechanism $2 a$ is operative for reduction of volume-surface diameter, $d_{32}$, while Mechanism $2 b$ is extremely effective in reducing the number diameters, $d_{\mathrm{N} 95}$ and $d_{\mathrm{N} 50}$, when fibers with diameter $<2 \mu \mathrm{m}$ are formed upon cooling.

\subsection{Melt-crystal fragmentation (Mechanism 3)}

The third mechanism for decreasing the emulsion drop size consists of bursting (fragmentation) of frozen platelets in the moment of their melting, Figure 7A. Our observations showed that the crystal domains in the platelet melt within a period of several seconds. In the systems stabilized with appropriate surfactants, the liquid (just melted) alkane domains dewet (separate from) the still frozen crystalline alkane domains, so that a single platelet splits into hundreds of separate droplets. ${ }^{19}$

\section{Effect of the initial drop size and cooling rate on melt-crystal fragmentation}

Mechanism 3 is effective only for frozen platelets, formed upon cooling. The bulky shapes which may form if the drops freeze in the initial stages of drop evolution, as well as the frozen ellipsoidal drops formed after capillary instability in the last stages of drop evolution do not fragment by Mechanism 3 upon heating. Therefore, the effectiveness of this mechanism depends primarily on the particle shapes, formed upon drop freezing.

For a given alkane-surfactant pair, the particle shapes obtained upon freezing depend on the initial drop size and cooling rate. ${ }^{21}$ In general, drops with diameters less than $10 \mu \mathrm{m}$ easily evolve up to the final stages of the evolutionary scheme, even at a cooling rate of $1.5 \mathrm{~K} / \mathrm{min}$. The obtained ellipsoidal drops do not disintegrate upon heating, as explained above. 
Therefore, higher cooling rates are more appropriate in such emulsions for realization of Mechanism 3. As an example, the mean drop diameter, $d_{V 50} \approx 4.6 \mu \mathrm{m}$, after one F/T cycle for $\mathrm{C}_{16}$ emulsion drops with $d_{i n i} \approx 11 \mu \mathrm{m}$, stabilized by $\mathrm{C}_{18} \mathrm{EO}_{20}$, when cooled at $1.5 \mathrm{~K} / \mathrm{min}$, while this size is $d_{V 50} \approx 2.8 \mu \mathrm{m}$ when the same emulsion is cooled at $20 \mathrm{~K} / \mathrm{min}$.

The bigger drops with $d_{i n i}>20 \mu \mathrm{m}$ need cooling rates lower than $1 \mathrm{~K} / \mathrm{min}$ to transform into platelets. Therefore, low cooling rates are more appropriate for the large droplets.

(A)
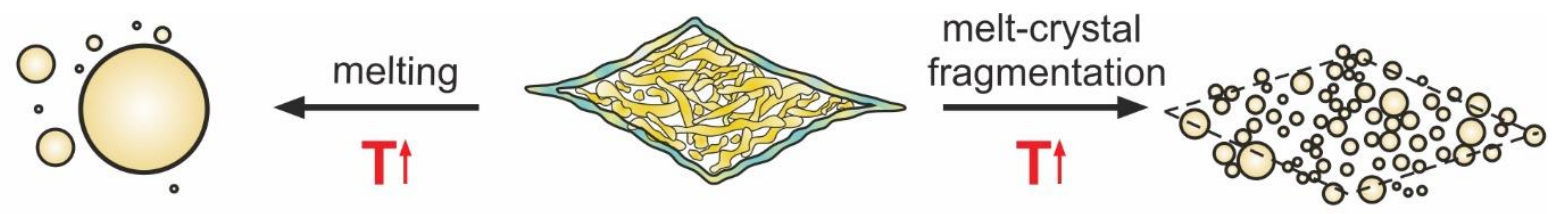

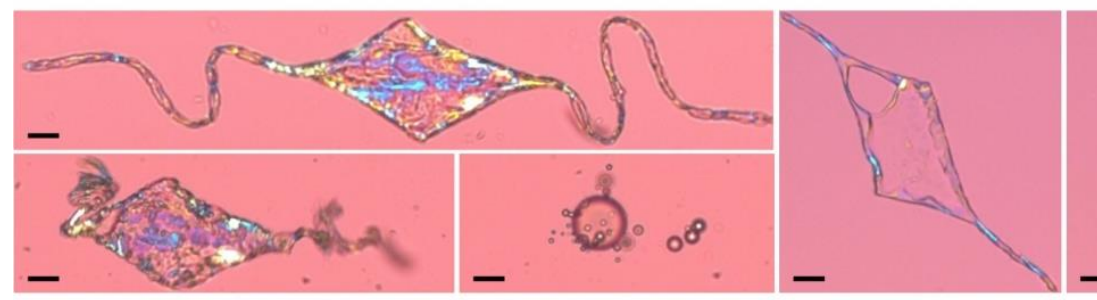

(B)

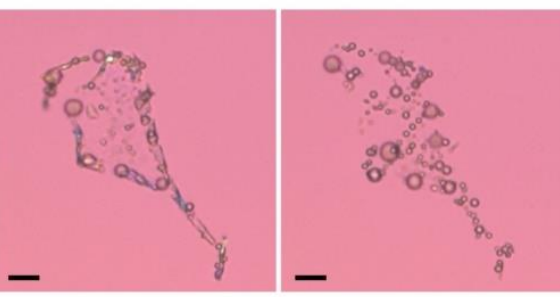

(C)

Figure 7. Melt-crystal fragmentation process (Mechanism 3). (A) Upon heating, platelets may melt into one big drop and several smaller droplets (B) or directly fragment into hundreds of small drops (C). (B) Typical melting process into one big and several small droplets, as observed with $\mathrm{C}_{16}$ drop, stabilized by $\mathrm{C}_{16} \mathrm{EO}_{20}$. (C) Process of melt-crystal fragmentation, leading to the formation of numerous small droplets, as observed with $\mathrm{C}_{17}$ drop, stabilized by $\mathrm{C}_{18} \mathrm{EO}_{20}$. Scale bars, $20 \mu \mathrm{m}$.

\section{Effect of surfactant-alkane combination}

Preparation of frozen platelets is a required step for occurrence of Mechanism 3, however, it is insufficient. As seen from Figure 7B,C, platelets with the same shape may or may not fragment upon melting, depending on the specific alkane-surfactant pair. The systems in which Mechanism 3 is very pronounced include $\mathrm{C}_{16}, \mathrm{C}_{17}$ and $\mathrm{C}_{18}$ emulsions, stabilized by $\mathrm{C}_{18} \mathrm{EO}_{20} ; \mathrm{C}_{14}$ and $\mathrm{C}_{15}$ emulsions, stabilized by $\mathrm{C}_{16} \mathrm{SorbEO}_{20}$; and $\mathrm{C}_{16}$ emulsion, stabilized by $\mathrm{C}_{18} \mathrm{EO}_{10}$. All these systems classify as emulsions, corresponding to surfactants from Group A, see Table 1. Thin platelets are formed in these emulsions upon cooling.

\section{Effect of heating rate}

As the melt-crystal fragmentation is observed during sample heating, one may expect this process to be affected by the heating rate. To check this possibility, we performed experiments at different heating rates, varied within two orders of magnitude - between 0.1 
and $10 \mathrm{~K} / \mathrm{min}$. However, we did not observe any significant difference in the sample behavior upon melting within this range of heating rates (for fixed all other conditions). The obtained drops after one or several freeze/thaw cycles had similar size distributions and the latter were influenced by the cooling rates only.

Analyzing the various physicochemical properties for the systems involved in Mechanism 3, we observed one common feature. For all systems exhibiting Mechanism 3, the interfacial tension surfactant solution-oil, $\sigma(T)$, decreases when the temperature was lowered toward the bulk melting temperature of the oil, $T_{m}$, see Figure 8. This trend is explained with the formation of a compact (dense) adsorption layer on the platelet surface before it freezes, see Figure $4 \mathrm{e}$ in ref [23]. As a result, the interfacial tension of the frozen alkane domains, covered with such dense surfactant layers, is lower and they are more easily de-wetted by the released melted alkane droplets upon platelet melting. As explained in ref. 19, this dewetting process is crucial for the observed platelet bursting into small droplets via Mechanism 3.

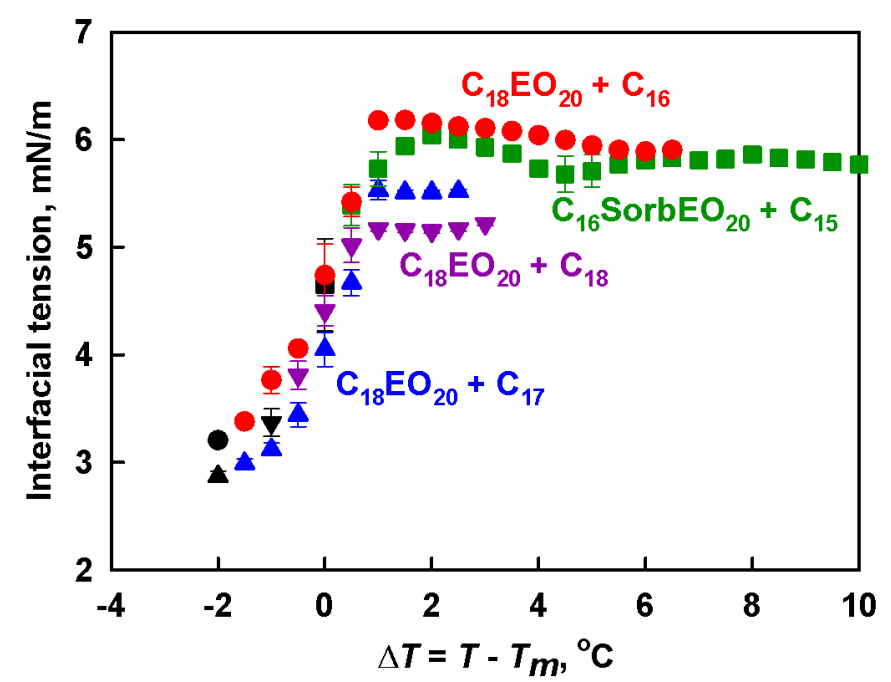

Figure 8. Dependence of the interfacial tension on the temperature difference, $\Delta T=T-T_{m}$, between the temperature of the sample and the bulk melting temperature of the alkane for the systems exhibiting Mechanism 3 (see Table S1). For all systems, in which Mechanism 3 is pronounced, the interfacial tension decreases when $T$ approaches $T_{m}$ from above.

However, our experiments showed that this decrease of the interfacial tension with the decrease of temperature is not a sufficient condition for self-emulsification via Mechanism 3. For example, a decrease of the interfacial tension is observed with $\mathrm{C}_{16}$ drops, stabilized by $\mathrm{C}_{18} \mathrm{TAB}$ surfactant. ${ }^{23,42}$ Nevertheless, no intensive crystal-melt fragmentation is observed upon melting of the platelets formed in the respective emulsions, see Supplementary Figure S3. 
With alkane-surfactant pairs, for which no decrease of interfacial tension is observed, a process of melt-crystal fragmentation has not been observed either.

In conclusion, Mechanism 3 is most effective for thin frozen platelets, formed upon emulsion cooling. To prepare such platelets, different cooling rates need to be applied, depending on the initial drop size - the bigger the drops, the lower cooling rate is needed. Intensive melt-crystal fragmentation may be expected only for the systems in which a decrease of the interfacial tension is observed around $T_{\mathrm{m}}$ upon cooling.

\subsection{Discussion - comparison of the relative effectiveness of different mechanisms}

In this section we compare the effectiveness of the different mechanisms of selfemulsification, with respect to the observed drop-size decrease. For this purpose we use the decrease of the mean volume-surface diameter of the drops, $d_{32}$, and the following relation:

$$
\text { Effectiveness }=\left(1-d_{32} / d_{32,0}\right)
$$

where $d_{32,0}$ is the mean drop diameter in the initial emulsion, whereas $d_{32}$ is the mean drop diameter in the emulsion, obtained after the cooling-heating cycle(s). If $d_{32}$ is not changed significantly after the cooling-heating cycle, the effectiveness is close to zero, whereas a very significant decrease of $d_{32}$ corresponds to effectiveness approaching $100 \%$.

\section{Effectiveness of Mechanism 1}

To determine the effectiveness of Mechanism 1 only, we performed the following type of experiment: we measured the initial drop size distribution, cooled the sample down to a temperature which is just above the freezing temperature of the drops and then heated the drops back to their liquid state. In this experiment, the drops are not solidified and, thus, the drop size decrease is due exclusively to Mechanism 1.

For oil drops with $d_{i n i} \approx 34 \mu \mathrm{m}$, stabilized by $\mathrm{C}_{18} \mathrm{EO}_{20}$, the drop size decreased to $d_{32} \approx$ $18 \mu \mathrm{m}$ for $\mathrm{C}_{17}$ and to $\approx 23 \mu \mathrm{m}$ for $\mathrm{C}_{16}$, after such an experiment with cooling rate of 0.2 $\mathrm{K} / \mathrm{min}$. Therefore, the effectiveness of Mechanism 1 was $\approx 30 \%$ (for $\mathrm{C}_{16}$ ) and $\approx 50 \%$ (for $\mathrm{C}_{17}$ ) at this cooling rate. The latter result for $\mathrm{C} 17$ is shown by empty square in Figure 9A. At higher cooling rate of $1.4 \mathrm{~K} / \mathrm{min}$, the effectiveness was lower - see the empty triangle in Figure 9A. 


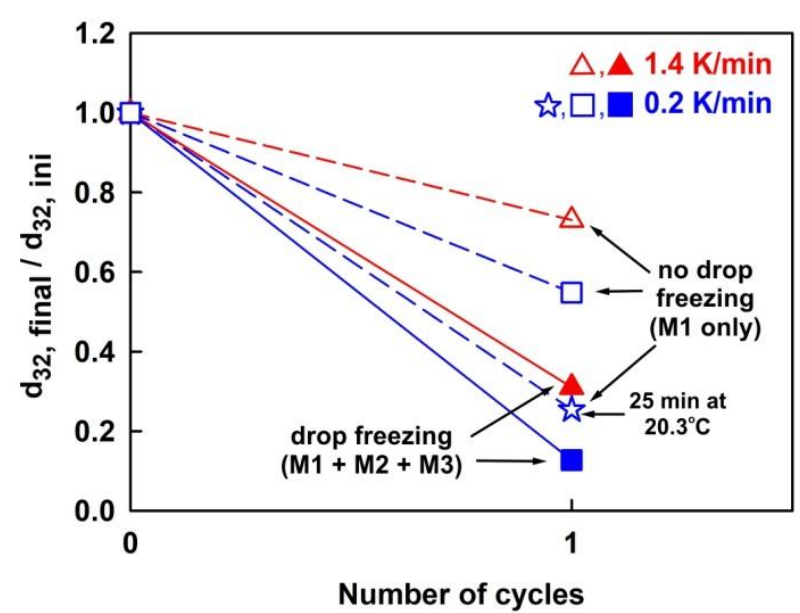

(A)

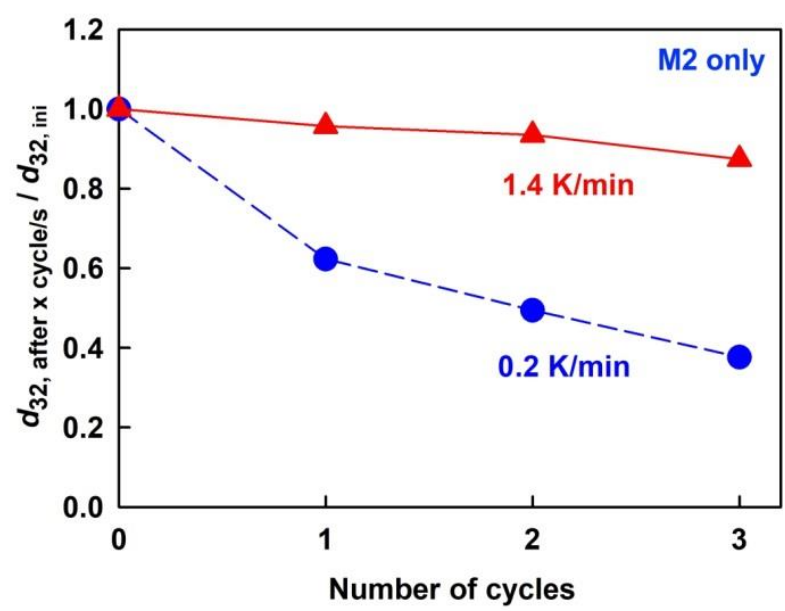

(B)

Figure 9. (A) Relative effectiveness of Mechanism 1. Comparison between the effectiveness of Mechanisms 1 and the combined effectiveness of all three mechanisms. The graphs present the ratio between the final $d_{32}$ diameter and the initial $d_{32,0}$ diameter, as a function of the number of cycles. Cycle " 0 " denotes the original sample, cycle " 1 " corresponds to one cycle which might be performed without freezing of the drops (empty symbols) or with freezing of the drops (solid symbols). Star symbol presents the results from an experiment in which the sample is cooled to $T=20.3{ }^{\circ} \mathrm{C}$ and this temperature is maintained for 25 min without drop freezing, before the sample is heated back to room temperature. All experiments in (A) are performed with $\mathrm{C}_{17}$ drops, $d_{i n i} \approx 34 \mu \mathrm{m}$, surfactant $\mathrm{C}_{18} \mathrm{EO}_{20}$. Drops are cooled at two different rates, $0.2 \mathrm{~K} / \mathrm{min}$ (blue symbols) and $1.4 \mathrm{~K} / \mathrm{min}$ (red symbols). (B) Effectiveness of Mechanism 2. Drop size decrease via Mechanism 2 in the system $\mathrm{C}_{16} / \mathrm{C}_{16} \mathrm{EO}_{20}, d_{\text {ini }} \approx 34 \mu \mathrm{m}$. Red symbols present data for cooling rates of $1.4 \mathrm{~K} / \mathrm{min}$ and the blue symbols - of $0.2 \mathrm{~K} / \mathrm{min}$; the heating rate is always $1.6 \mathrm{~K} / \mathrm{min}$.

When a whole freeze-thaw (F/T) cycle was applied to the same emulsions, the drop size became $d_{32} \approx 4.4 \mu \mathrm{m}$ for $\mathrm{C}_{17}$ and $d_{32} \approx 15 \mu \mathrm{m}$ for $\mathrm{C}_{16}$ for $0.2 \mathrm{~K} / \mathrm{min}$ cooling rate. In this type of experiment, when the drops freeze upon cooling, all three mechanisms are operative for the drop size decrease. Thus, the combined action of all three mechanisms leads to a drop size decrease by $55 \%$ (for $\mathrm{C}_{16}$ ) and by $85 \%$ (for $\mathrm{C}_{17}$, see the solid square in Figure 9A). At higher cooling rate of $1.4 \mathrm{~K} / \mathrm{min}$, the combined effectiveness of the three mechanisms is again lower (solid triangle in Figure 9A). Summarizing, Mechanism 1 contributes to $\approx 60 \%$ of the total effectiveness of the whole F/T cycle when the decrease of $d_{32}$ is compared.

As already discussed, to observe bursting via Mechanism 1, the drops need time to deform until they thin locally and break. To check whether we can improve the effectiveness of Mechanism 1 by providing more time for drop deformation, we performed another type of 
experiment. We cooled the sample to temperature slightly above the platelet freezing temperature and maintained this temperature for $25 \mathrm{~min}$ before heating up the emulsion. As seen from the empty star symbol in Figure 9A, Mechanism 1 was much more effective in this experiment and led to a drop size decrease by around $75 \%$. Therefore, we could improve significantly the effectiveness of Mechanism 1 using a properly optimized cooling regime.

\section{Effectiveness of Mechanism 2}

The separate effectiveness of Mechanism 2 can be determined from the data for the drop size decrease of $\mathrm{C}_{16}$ drops, stabilized by $\mathrm{C}_{16} \mathrm{EO}_{20}$, for which only this mechanism is operative, see Table 1. Figure 9B presents the data for drops with $d_{\text {ini }} \approx 34 \mu \mathrm{m}$, after 3 consecutive F/T cycles. At a cooling rate of $1.4 \mathrm{~K} / \mathrm{min}$, the drop size does not change even after 3 cycles. At this cooling rate, the drops evolve up to the platelet stages, but the platelets melt back into a single drop upon heating. At a cooling rate of $0.2 \mathrm{~K} / \mathrm{min}$, however, the drop size decreases slowly. At this cooling rate, the drops pass through the whole evolutionary scheme, including the stage of capillary instability. As discussed in section 2 above (Stage 1: Mechanism 2a), the drops, stabilized by surfactant from Group $B$ or $C$ (Table 2) usually separates its volume into two or three ellipsoidal drops after the process of capillary instability, see Figure 6A-D. Thus, the drop size decrease in $\mathrm{C}_{16} / \mathrm{C}_{16} \mathrm{EO}_{20}$ emulsion is due only to Mechanism 2. Note that the observed decrease in $d_{32}$ is due mainly to Mechanism $2 a$, while the decrease in $d_{\mathrm{N} 95}$ is due mainly to Mechanism $2 b$. The overall effectiveness of Mechanism 2 after one freeze-thaw cycle is $\approx 30 \%$ decrease in $d_{32}$.

\section{Effectiveness of Mechanism 3}

This mechanism is most operative when frozen platelets are formed. To isolate this mechanism from the others, we performed "shock" cooling of a $\mathrm{C}_{16}$ emulsion with $d_{\text {ini }} \approx 11$ $\mu \mathrm{m}$, stabilized by $\mathrm{C}_{18} \mathrm{EO}_{20}$, at a cooling rate of $\approx 20 \mathrm{~K} / \mathrm{min}$, see Movie 3. At such a high cooling rate, the drops (which normally would evolve through the whole evolutionary scheme) transform up to the platelet stage and freeze. When this emulsion was heated and the platelets melted, melt-crystal fragmentation via Mechanism 3 was observed, while Mechanisms 1 and 2 were not operative.

The decrease of $d_{32}$ in the above experiment was $\approx 75 \%$. The respective histogram of the drop size distribution by volume, after one F/T cycle, is presented with red bars in Figure 10 (the histograms for the initial emulsions are presented in Supplementary Figure S4). As 
seen from Figure 10A, the drop size distribution by volume is log-normal, with a peak around $2 \mu \mathrm{m}$. The respective $d_{\mathrm{V} 50}$ diameter is $\approx 2.8 \mu \mathrm{m}$. Most of the drops have diameters between 0.5 and $2.5 \mu \mathrm{m}$, as seen from the histogram by number, Figure 10B (red bars). Very similar results were obtained with $\mathrm{C}_{17}$ emulsions with $d_{\mathrm{ini}} \approx 34 \mu \mathrm{m}$, stabilized by $\mathrm{C}_{18} \mathrm{EO}_{20}$.

For comparison, with blue bars in the same figure we present the drop size distributions, obtained when the experiment with the same initial $\mathrm{C}_{16}$ emulsion is performed at low cooling rate of $0.2 \mathrm{~K} / \mathrm{min}$. In this case, $11 \mu \mathrm{m} \mathrm{C}_{16}$ drops, stabilized by $\mathrm{C}_{18} \mathrm{EO}_{20}$, transform through the whole evolutionary scheme, eventually forming ellipsoidal drops which extrude thin fibers before freezing. These drops do not burst via Mechanism 1, thus, the drop size decrease is mainly due to Mechanism 2. The mean volume-surface diameter after one F/T cycle at a cooling rate of $0.2 \mathrm{~K} / \mathrm{min}$ is very similar to that, obtained after "shock" cooling, $d_{32} \approx 2.7 \mu \mathrm{m}$ at $0.2 \mathrm{~K} / \mathrm{min}$ and $d_{32} \approx 2.6 \mu \mathrm{m}$ at $20 \mathrm{~K} / \mathrm{min}$. However, as seen from the histograms, these two emulsions have very different drop size distributions. After slow cooling of $0.2 \mathrm{~K} / \mathrm{min}$, the emulsion obtained via Mechanism 2 has bimodal distribution by volume, with peaks around 2 $\mu \mathrm{m}$ and $5.5 \mu \mathrm{m}$, Figure 10A (blue bars). The drop size distribution by number is log-normal and most of the drops have diameters around $1 \mu \mathrm{m}\left(d_{\mathrm{N} 84} \approx 1.4 \mu \mathrm{m}\right.$ and $\left.d_{\mathrm{N} 95} \approx 2.2 \mu \mathrm{m}\right)$. The reason is that the thin fibers, extruded upon cooling, disintegrate upon heating and form thousands of small droplets, while the main fraction of the oil remains in the large ellipsoidal drops which do not undergo melt-crystal fragmentation (it requires melting platelets) and remain as large melted drops after the cycle.

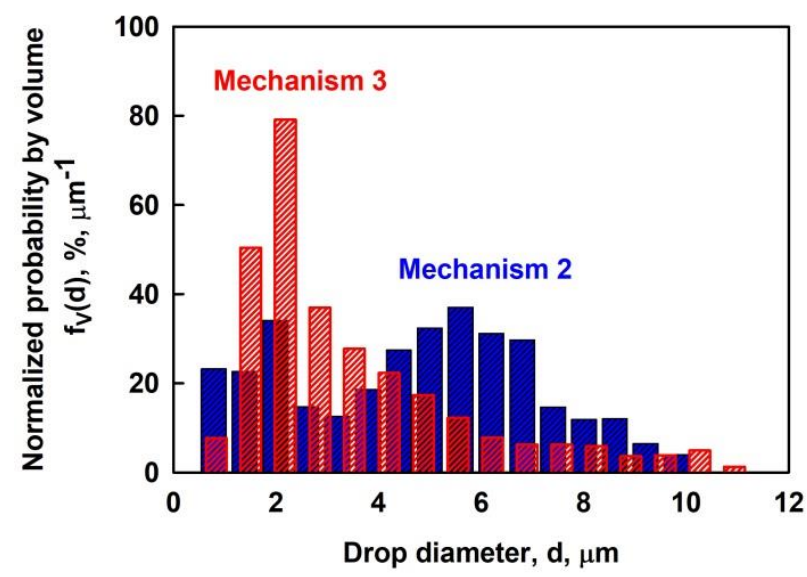

(A)

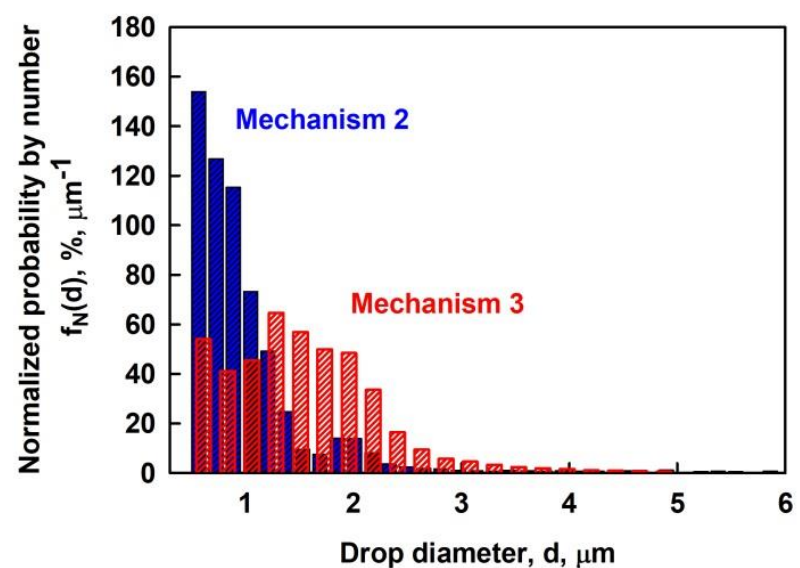

(B)

Figure 10. Relative effectiveness of Mechanism 3. Comparison between the drop size distributions (A) by volume and (B) by number, obtained after one F/T cycle, at two cooling rates $-0.2 \mathrm{~K} / \mathrm{min}$ (blue bars, Mechanism 2 prevailing) and $20 \mathrm{~K} / \mathrm{min}$ (red bars, Mechanism 3 dominating). In both cases, the heating rate is $1.6 \mathrm{~K} / \mathrm{min}$. These experiments are performed with $\mathrm{C}_{16}$ drops with $d_{\text {ini }} \approx 11 \mu \mathrm{m}$, stabilized by $\mathrm{C}_{18} \mathrm{EO}_{20}$. 
In conclusion, Mechanism 3 may reduce $d_{32}$ by around $75 \%$ after just one F/T cycle. For small drops, which can evolve up to the last stage of the evolutionary scheme, this effectiveness is comparable with the effectiveness of Mechanism 2. However, when the drops reduce their size by Mechanism 2, the obtained emulsions are typically bimodal, while Mechanism 3 leads to monomodal log-normal distribution by volume, as usually observed with the conventional emulsification methods.

\section{Conclusions}

We present a systematic study with a wide range of alkane-surfactant pairs of the mechanisms leading to drop bursting and self-emulsification in cyclically cooled/heated emulsions. The obtained results reveal that this process can be applied to various systems and three main mechanisms are responsible for the observed drop bursting process:

Most effective for drop size decrease is Mechanism 3 (melt-crystal fragmentation) for which $d_{32}$ may decrease by more than $75 \%$ after a single freeze-thaw cycle if appropriate conditions are used. For large initial drops (ca. 20 to $40 \mu \mathrm{m}$ ) this may require slow cooling while for smaller initial drops (ca. 5 to $15 \mu \mathrm{m}$ ) faster cooling may be required to freeze the deformed drops at the stage of flat platelets.

The effectiveness of Mechanism 1 (puncture of the fluid platelets upon cooling) characterized by the observed decrease of $d_{32}$ after one cooling-heating cycle, is around 35\%, though this can be increased up to $70 \%$ if an appropriate cooling protocol is applied. For example, we have observed this when the drops were cooled to a temperature which is just above their freezing temperature and the emulsion - stored at this temperature for a longer period of time (e.g. 15 to $30 \mathrm{~min}$ ), which ensures more time for drop deformation and puncturing.

The effectiveness of Mechanism 2 (hydrodynamic instability of melting fibers) depends strongly on the initial drop size and the cooling rate, because the bigger drops need much longer time to evolve to the final stages of the evolutionary process and to extrude the same fraction of oil, as compared to the smaller drops (the extruded fibers are with similar diameter for given alkane-surfactant pair, no matter the drop size). For big drops, the effectiveness of Mechanism 2 is around 30\%, while for small drops it can reach the effectiveness of Mechanism 3 (up to $70 \%$ ). However, drops formed in Mechanism 2 usually have bimodal distribution, while the emulsions are with much smaller polydispersity when Mechanism 3 is predominant. 
These results show that the self-emulsification procedure via F/T cycles of the dispersed drops could be very effective under appropriate conditions. These conditions could be optimized to improve the effectiveness and to control (to some extent) the drop size distribution. Most appropriate for realization of this procedure are the surfactants with taillength comparable to the length of the alkane molecules, for which the drop deformation starts above the melting temperature of the bulk oil, $T_{\mathrm{m}}$, viz. those falling in Group A, according to the classification from ref. [21]. The selection of appropriate cooling protocol is very important to obtain significant reduction of the drop diameter, $d_{32}$, by activating the most appropriate mechanism(s) for the respective alkane-surfactant pair.

The main advantages of this procedure are: (1) the low temperature of emulsion handling, without unnecessary heating which could deteriorate temperature-sensitive ingredients; (2) the possibility to form micrometer and sub-micrometer droplets after one to several F/T cycles; and (3) the scalability to industrial capacities at relatively high energy efficiency. ${ }^{19}$

Acknowledgments. The authors gratefully acknowledge the financial support to S.K.S., EMATTER (\# 280078) and Proof-of-Concept ShipShape (\# 766656) by the European Research Council (ERC) and by the Scientific Research Fund of Sofia University (project no. 80-10-225). The study falls under the umbrellas of the European network COST MP 1305 and the Horizon 2020 project "Materials Networking" (ID: 692146-H2020-eu.4.b). The authors are grateful to Dr. Ivan Lesov (Sofia University) for the useful discussions. 


\section{References}

1. Walstra, P.; Geurts, T.; Noomen, A.; Jellema, A.; van Boekel, A.A.J.S. Dairy Technology. 1999, Marcel Dekker: New York.

2. Walstra, P. Formation of emulsions. In Encyclopedia of Emulsion Technology. 1983, Marcel Dekker: New York, Chapter 2.

3. Schubert, H.; Engel, R. Product and formulation engineering of emulsions. Chem. Eng. Res. Design, 2004, 82, 1137-1143. doi: 10.1205/cerd.82.9.1137.44154

4. Coulaloglou, C.; Tavlarides, L. Description of interaction processes in agitated liquidliquid dispersions. Chem. Engin. Sci. 1977, 32, 1289-1297. doi: 10.1016/00092509(77)85023-9

5. Calabrese, R.; Chang, T.; Dang, P. Drop breakup in turbulent stirred-tank contraction. Part I: Effect of dispersed-phase viscosity. AIChE Journal 1986a, 32, 657-666. doi: 10.1002/aic.690320416

6. Davies, J. Drop sizes of emulsions related to turbulent energy dissipation rates. Chem. Eng. Sci. 1985, 40, 839-842. doi: 10.1016/0009-2509(85)85036-3

7. Sprow, F. Distribution of drop sizes produced in turbulent liquid-liquid dispersion. Chem. Eng. Sci. 1967, 22, 435-442. doi: 10.1016/0009-2509(67)80130-1

8. Vladisavljević, G.; Williams, R. Recent developments in manufacturing emulsions and particulate products using membranes. Adv. Colloid Interface Sci. 2000, 113, 1-20. doi: 10.1016/j.cis.2004.10.002

9. Christov, N.; Ganchev, D.; Vassileva, N.; Denkov, N.; Danov, K.; Kralchevsky, P. Capillary mechanisms in membrane emulsification: oil-in-water emulsions stabilized by Tween 20 and milk proteins. Colloids Surf. A 2002, 209, 83-104. doi: 10.1016/S09277757(02)00167-X

10. Bibette, J.; Leal-Calderon, F.; Poulin, P. Emulsions: basic principles, Rep. Progress Phys. 1999, 62, 969-1033. doi: 10.1088/0034-4885/62/6/203

11. Mason, T.; Wilking, J.; Meleson, K.; Chang, C.; Graves, S. Nanoemulsions: formation, structure, and physical properties. J. Phys. Condens. Matter 2006, 18, R635-R666. doi: 10.1088/0953-8984/18/41/R01

12. Solans, C.; Sole I. Nano-emulsions: formation by low energy methods. Current Opin. Colloid Interface Sci. 2012, 17, 246-254. doi: 10.1016/j.cocis.2012.07.003

13. Perazzo, A.; Preziosi, V.; Guido, S. Phase inversion emulsification: Current understanding and applications, Adv. Colloid Interface Sci. 2015, 222, 581-599. doi: 10.1016/j.cis.2015.01.001

14. Pouton, C. Formulation of self-emulsifying drug delivery systems. Adv. Drug Delivery Rev. 1997, 25, 47-58. doi: 10.1016/S0169-409X(96)00490-5

15. Gursoy R.; Benita S. Self-emulsifying drug delivery systems (SEDDS) for improved oral delivery of lipophilic drugs. Biomed. Pharmacother. 2004, 58, 173-82. doi: 10.1016/j.biopha.2004.02.001 
16. Sitnikova, N.; Sprik, R.; Wegdam, G.; Eiser, E.; Spontaneously formed transanethol/water/alcohol emulsions: mechanism of formation and stability. Langmuir 2005, 21, 7083-7089. doi: 10.1021/la0468161

17. Vitale, S.; Katz, J. Liquid droplet dispersions formed by homogeneous liquid-liquid nucleation: "The Ouzo effect". Langmuir 2003, 19, 4105-4110. doi: 10.1021/1a026842o

18. Ganachaud, F.; Katz J. Nanoparticles and nanocapsules created using the Ouzo effect: Spontaneous emulsification as an alternative to ultrasonic and high-shear devices. ChemPhysChem 2005, 6, 209-216. doi: 10.1002/cphc.200400527

19. Tcholakova, S.; Valkova, Z.; Cholakova, D.; Vinarov, Z.; Lesov, I.; Denkov, N.; Smoukov, S. Efficient Self-Emulsification via Cooling-Heating Cycles. Nature Comm. 2017, 8: 15012. doi: 10.1038/ncomms 15012

20. Denkov, N.; Tcholakova, S.; Lesov, I.; Cholakova, D.; Smoukov, S. Self-shaping of oil droplets via the formation of intermediate rotator phases upon cooling. Nature 2015, 528, 392-395. doi:10.1038/nature16189

21. Cholakova, D.; Denkov N.; Tcholakova S.; Lesov I.; Smoukov S. Control of drop shape transformations in cooled emulsions. Adv. Colloid Interface Sci. 2016, 235, 90-107. doi:10.1016/j.cis.2016.06.002

22. Cholakova, D.; Valkova, Z.; Tcholakova, S.; Denkov, N.; Smoukov, S. "Self-Shaping" of multicomponent drops. Langmuir 2017, 33, 5696-5706. doi: 10.1021/acs.langmuir.7b01153

23. Denkov, N.; Cholakova, D.; Tcholakova, S.; Smoukov, S. K. On the mechanism of drop self-shaping in cooled emulsions. Langmuir 2016, 32, 7985-7991. doi: 10.1021/acs.langmuir.6b01626

24. Small, D. M. The Physical Chemistry of Lipids. From Alkanes to Phospholipids. Plenum: New York, 1986. doi: 10.1002/pol.1987.140250211

25. Sirota, E.; King, H.; Singer, D.; Shao H. Rotator phases of the normal alkanes: An x-ray scattering study. J. Chem. Phys. 1993, 98, 5809-5824. doi: 10.1063/1.464874

26. Sirota, E.; Singer, D. Phase transitions among the rotator phases of the normal alkanes, $J$. Chem. Phys. 1994, 101, 10873-10882. doi: 10.1063/1.467837

27. Sirota, E.; Herhold, A. Transient phase-induced nucleation. Science 1999, 283, 529-532. doi: $10.1126 /$ science.283.5401.529

28. Ueno, S.; Hamada, Y.; Sato, K. Controlling polymorphic crystallization of n-alkane crystals in emulsion droplets through interfacial heterogeneous nucleation. Cryst. Growth Des. 2003, 3, 935-939. doi: 10.1021/cg0300230

29. Shinohara, Y.; Takamizawa, T.; Ueno, S.; Sato, K.; Kobayashi, I.; Nakajima, M.; Amemiya, Y. Microbeam X-Ray diffraction analysis of interfacial heterogeneous nucleation in n-hexadecane inside oil-in-water emulsion droplets. Cryst. Growth Des. 2008, 8, 3123-3126. doi: 10.1021/cg701018x

30. Shinohara, Y.; Kawasaki, N.; Ueno, S.; Kobayashi, I.; Nakajima, M.; Amemiya Y. Observation of the transient rotator phase of n-hexadecane in emulsified droplets with 
time-resolved two-dimensional small- and wide-angle X-Ray scattering. Phys. Rev. Lett. 2005, 94, 097801-1 - 097801-4. doi: 10.1103/PhysRevLett.94.097801

31. Haas, P.; Goldstein, R.; Smoukov, S.; Cholakova, D.; Denkov, N. Theory of shapeshifting droplets. Phys. Rev. Lett. 2017, 118, 088001-1 - 088001-5. doi: 10.1103/PhysRevLett.118.088001

32. Kandori, K.; Gaonkar, A. (Ed.). Applications of microporous glass membranes: membrane emulsification. Elsevier 1995, 113. doi: 10.1016/B978-044481500-2/50009-8

33. Charcosset, C.; Limayem, I.; Fessi, H. The membrane emulsification process - a review. J. Chem. Technol. Biotechnol. 2004, 79, 209-218. doi: 10.1002/jctb.969

34. Joscelyne, S.; Tragardh, G. Membrane emulsification - a literature review. J. Membr. Sci. 2000, 169, 107-117. doi: 10.1016/S0376-7388(99)00334-8

35. Nakashima, T.; Shimizu, M.; Kukizaki, M. Membrane emulsification by microporous glass. Key Eng. Mater. 1992, 61-62, 513-516. doi: 10.4028/www.scientific.net/KEM.6162.513

36. Newton, R. H.; Haffegee, J. P.; Ho, M. H. Polarized light microscopy of weakly birefringent biological specimens. J. Microsc. 1995, 180, 127-130. doi: 10.1111/j.13652818.1995.tb03667.x

37. Holmberg, K. Handbook of applied surface and colloid chemistry. Vol. 2 Ch. 16 Identification of lyotropic liquid crystalline mesophases. John Wiley \& Sons 2001, 299332.

38. Denkova, P.; Tcholakova, S.; Denkov, N.; Danov, K.; Campbell, B.; Shawl, C.; Kim, D. Evaluation of the Precision of Drop-Size Determination in Oil/Water Emulsions by LowResolution NMR Spectroscopy. Langmuir 2004, 20, 11402-11413. doi: $10.1021 / 1 \mathrm{a} 048649 \mathrm{v}$

39. Rotenberg, Y.; Boruvka, L.; Neumann, A. W. Determination of surface tension and contact angle from shapes of axisymmetric fluid interfaces. J. Colloid. Interface Sci. 1983, 93, 169-183. doi: 10.1016/0021-9797(83)90396-X

40. Hoorfar, M.; Neumann, A. W. Recent progress in axisymmetric drop shape analysis (ADSA). Adv. Colloid Interface Sci. 2006, 121, 25-49. doi: 10.1016/j.cis.2006.06.001

41. Bird, R. B.; Stewart, W. E.; Lightfoot, E. N. Transport Phenomena, Example 12.1-2, pp 376-378, 2nd ed., Wiley, NY, 2002.

42. Guttman, S.; Sapir, Z.; Schultz, M.; Butenko, A.; Ocko, B.; Deutsch, M.; Sloutskin, E. How faceted liquid droplets grow tails. Proc. Natl. Acad. Sci. U.S.A. 2016, 113, 493-496. doi: 10.1016/j.cocis.2016.02.002 


\section{Table of Contents Graphic}

"Mechanisms and control of self-emulsification upon freezing and melting of dispersed alkane drops" (by Valkova et al.)

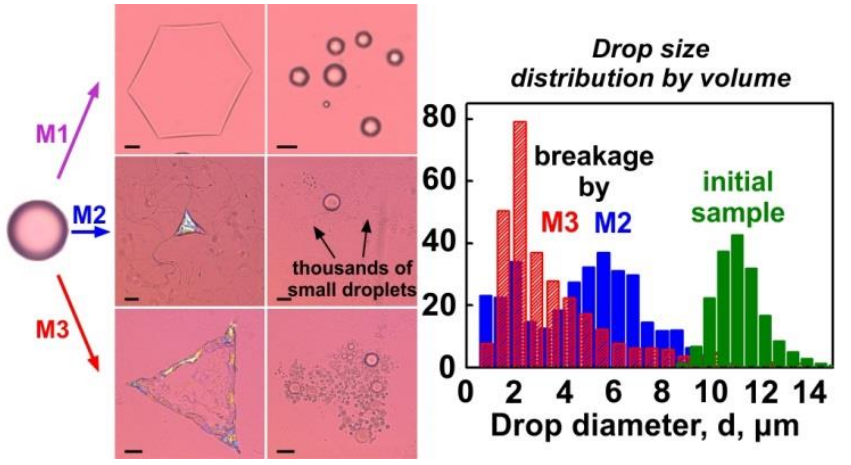

